\title{
House Prices, Sales and Time on the Market: A Search-Theoretic Framework
}

\author{
Antonia Díaz \\ Universidad Carlos III
}

\author{
Belén Jerez ${ }^{\dagger}$ \\ Universidad Carlos III
}

\begin{abstract}
Some salient stylized facts of the housing sector are hard to reconcile with the Walrasian market paradigm. These include the co-movement of prices and sales and their negative correlation with average time on the market. We build a search equilibrium model of the housing market which captures the illiquidity of housing assets. In the model, agents experience idiosyncratic shocks that affect how much they value their residence (e.g. their job or their size changes over time). When hit by a shock, agents become mismatched and seek to move, but they take time to locate an appropriate unit. Competitive forces operate in the housing market since by posting lower prices sellers get more visits and sell their property faster. We characterize a stationary competitive search equilibrium when the housing stock is fixed. We calibrate our economy to reproduce selected aggregate statistics of the U.S. economy. We find that the model's predictions are consistent with the observed joint behavior of prices, sales and time on the market. This is not the case when we consider the frictionless Walrasian version of the model.
\end{abstract}

Keywords: House prices, sales, time on the market, search frictions, competitive search equilibrium.

JEL Classification: R31, D83, D40

\footnotetext{
${ }^{*}$ We thank Melvyn Coles, Andrés Erosa, Miquel Faig, Javier Fernández Blanco, Martin Gervais, Ed Green, Tim Kehoe, Matthias Kredler, Claudio Michelacci, Facundo Piguillem, Fabian Postel-Vinay, Guillaume Rocheteau, Peter Rupert, and Manuel Santos for their comments, and participants of the SED Conference at MIT 2008, III REDg DGE Macroeconomics Workshop at Madrid 2008, XIII Workshop on Dynamic Macroeconomics at Vigo 2008, and seminars at Banco de España, University of Bristol, Universidad Carlos III, University of Essex and Universidad de Salamanca. Díaz thanks the Dirección General de Investigación, project SEJ2007-65169/ECON, for financial support. Jerez thanks Spanish DGCYT (projects SEJ2007- 66820 and SEJ2004-07861 and Ramón y Cajal Program).

${ }^{\dagger}$ Corresponding author: Belén Jerez, Departament of Economics. Universidad Carlos III de Madrid, Calle Madrid, 126, Getafe 28903 Madrid, Spain. E-mail: mjerez@eco.uc3m.es. Ph: +34-91-624-9633.
} 


\section{Introduction}

A household's residence is usually its largest single asset. In the US, household real net housing wealth is about half of the level of tangible financial assets held by households on average (according to the Board of Governors of the Federal Reserve System's data for 2006). Despite its importance, our understanding of many aspects of the housing sector is, at best, incomplete. In particular, the literature has emphasized the following stylized facts of the housing sector in the US. First, prices and sales co-move (with correlation 0.78), prices are more volatile than GDP (displaying positive auto-correlation at high frequencies), and sales are even more volatile (Ríos-Rull and Sánchez-Marcos 2007). Also, prices and sales are negatively correlated with average time on the market, which is also quite volatile (see Krainer 2001, or Krainer 2008). Attempts to build an equilibrium model of the housing market that is consistent with these facts have proven difficult. One reason in our view is that the housing market displays some key features that are hard to reconcile with the Walrasian market paradigm.

First and foremost, houses are illiquid long-lived assets. They are costly to sell and buy, they can be partially financed, and they are not movable. ${ }^{1}$ Incorporating frictions along these lines into the Walrasian set-up helps to match the observed price volatility (see, for instance, Nakajima 2005 or VanNieuwerburgh and Weill 2006), but it is still hard to explain the positive co-movement of prices and sales (see Ríos-Rull and Sánchez-Marcos 2007). Second, there is evidence that the degree of liquidity of housing assets changes over time. That is, adjustments in the housing market seem to take place not only through prices and quantities, as in a Walrasian world, but also through the degree of liquidity; i.e., how easy/hard it is to sell a property. Whereas in "hot" real estate markets prices and sales rise and time-on-the-market falls (properties sell faster), in "cold" real estate markets prices and sales fall and time-on-the-market rises (see Krainer 2001). ${ }^{2}$

The specific aim of this work is to build a theoretic framework for the study of house price formation. In order to do so, we focus our attention on two features of the housing

\footnotetext{
${ }^{1}$ See Díaz and Luengo-Prado (2008) for a model of tenure choice with housing adjustment costs and collateralized borrowing constraints, for instance.

${ }^{2}$ Krainer (2008) shows, for instance, that selling times in California range from three weeks in the recent boom to three months in early 90 s market slowdown.
} 
sector: (1) prices and volume of sales are positively correlated and (2) time-on-the-market falls when prices increase. To this end, we depart from standard macroeconomic models in two dimensions. Firstly, we assume that there are search frictions in the housing market. In our view search theory is a natural paradigm to study housing markets precisely because it captures the aforementioned illiquidity of housing assets and the fact that the degree of liquidity may change over time depending on market conditions. Anyone who has gone through the process knows it takes time and resources to buy and sell housing units. There are costs of acquiring relevant information in each potential transaction. Also, buyers' valuations typically depend not only on attributes of the units for sale which are observable or verifiable at a negligible cost through a phone call or via email (e.g. size, number of bedrooms and bad rooms, neighborhood, proximity to public transportation, age, floor, ...). They also depend on idiosyncratic features of the unit that can only be verified by visiting and inspecting them. As a result, it takes time to locate appropriate units and to make a purchase. For instance, according to the National Association of Realtors for 2006, a typical buyer visited 10 units on average before purchasing one, and on average took about 8 weeks to purchase a home. Secondly, we assume that the stock of housing assets is not capital - which is essentially lagged output. Instead, we take the opposite extreme and model the stock of houses as given. This should be seen as a first step towards increasing our understanding of the process of house price formation.

In this paper we build a dynamic model economy with the minimum degree of heterogeneity needed so that the mechanics of price formation appear clearly. Specifically, we consider an environment similar to Wheaton (1990) and Krainer (2001) where symmetric households experience shocks throughout their life-time that affect how much they value their residence. When hit by a shock, households may become mismatched with their current residence. Such households may then seek to buy an appropriate unit and sell the current one. For instance, if an agent living and working in NYC gets a job in LA, the agent will need to move. ${ }^{3}$ That is, there does not exist a centralized market where one can buy or sell a unit instantaneously at the market price. Instead, sellers take time to find potential buyers (and vice versa). Also, not all the units that buyers visit are suitable for them, so it takes time to close a deal.

\footnotetext{
${ }^{3}$ In our benchmark model, we abstract away from the rental housing market.
} 
Unlike in Wheaton (1990) and Krainer (2001) where search is purely random and prices are determined by Nash bargaining, we model the process of price determination by adopting a notion of competitive equilibrium for search environments (see Montgomery 1991, Peters (1991), Moen (1997), Shimer (1996), and Burdett, Shi, and Wright (2001), among others). There, sellers compete by posting prices in other to attract buyers. Buyers then observe all the posted prices and restrict their search to the most attractive offer. This means that by posting lower prices sellers can attract more buyers on average. There is evidence that competitive forces are present in the housing market. For instance, Merlo and Ortalo-Magné (2004) provide evidence for the UK that, by listing lower prices, sellers increase the number of visits and offers they get, and sell their property faster. ${ }^{4}$

The competitive search equilibrium allocation is constrained efficient (see Moen (1997)). Specifically, since buyers and sellers are symmetric (and the matching function is differentiable), the competitive search equilibrium notion is equivalent to assuming that buyers and sellers bargain over the surplus according to the bargaining rule in Hosios (1990) (see Moen (1997)). As shown by Hosios, this rule attains an efficient division of the surplus and internalizes the search externalities.

We characterize a search equilibrium and analyze the qualitative effects on the steadystate of changes in exogenously given factors like the vacancy rate and the probability of becoming mismatched. Next, we calibrate our model economy to reproduce some selected statistics of the US economy, namely, the vacancy rate, the average time households stay in the same unit (i.e., expected tenure length), and the average time it takes to buy a unit. We find, for instance, that an increase in the probability that households become mismatched (say due to greater geographical mobility) increases sales and reduces selling times. The effect on the price is positive for parameter values consistent with our calibration targets. A fall in the vacancy rate (due to an increase in the population relative to the housing stock) has a similar effect in that it reduces selling times, increases sales, and also prices (for reasonable parameter values). Critically, the elasticity of the price is very high in both cases. For instance, if the vacancy rate rises from 1.5 percent to 4 percent, the price falls by a factor of 16 . Time to sell increases from 8 weeks to almost 5 months.

\footnotetext{
${ }^{4}$ Our model is too simple to capture the rich details of the strategic interaction between buyers and sellers. See, however, Merlo, Ortalo-Magné, and Rust (2007) and Albrecht, Anderson, Smith, and Vroman (2007).
} 
An interesting exercise is to analyze the Walrasian version of our model economy by eliminating the frictions. In the last section of the paper we show that the positive correlation of prices and sales and the stark reaction of prices to demand changes cannot be delivered by the Walrasian version of the model.

In sum, we view the simple benchmark model in this paper as a first step that, while leaving out several important factors that affect the housing market, can account for the co-movement of prices, sales and liquidity we see in the data, as well as the stark reaction of prices to demand changes. This co-movement arises solely from the interaction of search frictions and competitive forces. Our immediate next goal is to introduce aggregate uncertainty. We then plan to introduce housing construction, and embed the model in general equilibrium to study several important issues, such as the effect of changes in financial markets, rental housing markets, and population growth (e.g. immigration). ${ }^{5}$

Other authors have proposed search models as a natural benchmark to study the housing market, even though their focus is different from ours (see Wheaton 1990, Yavaş 1992, Williams 1995, Arnold 1999, Krainer 2001, Albrecht, Anderson, Smith, and Vroman 2007, Yui and Zhang 2007, and Hendel, Nevo, and Ortalo-Magné 2007, among others). Our objective is in this paper is to build a fully calibrated model that is able to reproduce the observed joint behavior of prices, sales and time on the market. One advantage of our model is that it is also parsimonious, so we can also shed light on the basic economic mechanisms underlying our results.

A key modeling difference with respect to the existing literature has to do with the equilibrium notion we adopt. We have chosen competitive search for two main reasons. First, with competitive search the share of the surplus depends on the number of buyers per seller in the market which is endogenous. This means that prices fluctuate more with competitive search than with Nash bargaining where the sharing rule is exogenously fixed. In fact, our calibration exercise--where we adopt the matching function derived by Peters (1991) for these kind of symmetric competitive search environments-shows that the sharing rule reacts a lot to demand changes. Second, as frictions vanish, the competitive search

\footnotetext{
${ }^{5}$ The interaction of financial constraints and search frictions are studied, for instance, by Genesove and Mayer (1997), and Stein (1995).
} 
equilibrium converges to the Walrasian benchmark (while this is not the case with Nash bargaining). This is interesting because it allows for us to compare the search and the Walrasian frameworks.

The papers by Krainer (2001) and Yui and Zhang (2007) are the closest to ours. Both models generate a positive co-movement in prices, sales and liquidity, but the mechanisms operating there are slightly different, and the models are not calibrated to the data. Krainer (2001) shows that if households' valuations are subject to aggregate shocks that are persistent enough, prices, sales and liquidity are higher in the high than in the low aggregate state. In our model, changes in the likelihood of idiosyncratic shocks (or in the vacancy rate) also generate this co-movement. ${ }^{6}$ Yui and Zhang (2007) characterize a search equilibrium with free entry of sellers. Their equilibrium notion is halfway between the Nash bargaining and the competitive search notion. ${ }^{7}$ They find a positive co-movement between in prices, sales and liquidity when buyers differ in their waiting costs and their search intensity is endogenous (but without the latter the movement in liquidity is counterfactual). Our model delivers this co-movement in a simpler set-up with symmetric buyers and sellers and no choice of search intensity.

The rest of the paper is organized as follows: Section 2 presents our model economy. In Section 3 we describe our notion of equilibrium, we characterize the steady state and discuss our analytical results. Section 4 presents the benchmark calibration of our model economy and conducts various across steady state exercises. We turn to analyze the results of the Walrasian version of our model economy in Section 5. Section 6 concludes.

\footnotetext{
${ }^{6}$ This mechanism arises from competitive search forces and is not present in Krainer's model (e.g. there more frequent idiosyncratic shocks increase prices but decrease liquidity and sales).

${ }^{7}$ While prices are determined by ex post Nash bargaining, there are different "submarkets" where sellers can choose to trade ex ante. Buyers, however, cannot move across submarkets as in a competitive search equilibrium (see Moen 1997).
} 


\section{The model economy}

\section{$2.1 \quad$ Environment}

There is a measure $N$ of infinitely-lived symmetric households who derive utility from the services of housing units. Houses are durable assets which are indivisible (e.g. one either owns a unit or does not, but cannot own "half a unit") and illiquid (it takes time to buy and sell a unit). For simplicity, we assume that households want to consume the services of a single unit each period (i.e., they assign zero value to additional units). We also assume that the utility of being homeless is $-\infty$. Utility is transferable ${ }^{8}$ and households discount the future at rate $\beta \in(0,1)$.

In our benchmark model, the stock $H$ of housing units is exogenously fixed and is owned by the households. We abstract away from the rental housing market, and assume that units do not depreciate over time. We also assume for simplicity that households own either one or two units, with $H \in(N, 2 N) .{ }^{9}$ The measure of households who own two units is then $H-N$. These households will seek to sell their second unit, which yields no value to them.

The flow (per period) utility $v_{t}$ a household derives from its residence changes over time due to idiosyncratic factors (e.g. changes in job location or household size). To keep things simple assume that $v_{t}$ can be either high or low: $v_{t} \in\{\underline{v}, \bar{v}\}$ where $0<\underline{v}<\bar{v}$. That is, each period $t$ households can be either matched (living in a unit which yields $\bar{v}$ ) or mismatched (living in a unit which yields $\underline{v}$ ). For example, households are matched if they live and work in the same area (or if their residence size fits the household's size), and they are mismatched otherwise. Each period $t$ a fraction of the matched households are hit by an idiosyncratic shock (e.g. their job or size changes) as a result of which they become mismatched. Specifically, we assume that matched households who own one unit become mismatched with probability $\alpha \in(0,1)$ each period. We assume that preference shocks are realized in such a way that $\alpha$ the Law of Large Numbers holds, so $\alpha$ is also the fraction of

\footnotetext{
${ }^{8}$ This assumption is standard in the search and matching literature.

${ }^{9}$ Suppose there is an upper bound on inventories so no one can own more than two units. If, in period 0 , the housing stock is distributed so some households own one and others own two units, then that will also be the case in all the periods that follow (as no one owning a single unit will sell it no matter how high the price is, and no one can buy a third unit).
} 
these households who become mismatched each period. ${ }^{10}$

Given the above, households can be in one of three states each period: matched with one unit (not seeking to trade), mismatched with one unit (seeking to buy an appropriate unit), and matched with two units (seeking to sell the unit they do not value). Denote the measure of households in each of these states by $n_{t}, b_{t}$ and $s_{t}$. These measures must add up to the total population, so

$$
N=n_{t}+b_{t}+s_{t}
$$

Also, the distribution of the housing stock among the households implies

$$
H=n_{t}+b_{t}+2 s_{t}
$$

As we have already noted, $s_{t}=H-N$ from (1) and (2). Hence, there will be a constant measure $H-N$ of houses for sale each period. The vacancy rate is the fraction of houses for sale relative to the housing stock, $V \equiv(H-N) / H$, and will be one of the key variables in our analysis.

Two remarks are in order here. First, we assume that households who are matched with one unit do not participate in the housing market. Since these are the households who face preference shocks, buying a second unit would serve as an insurance device against these shocks. ${ }^{11}$ The reason why we rule this out in our benchmark model is to keep all buyers symmetric, as this greatly simplifies the competitive search equilibrium characterization.

\footnotetext{
${ }^{10}$ Alternatively, we could consider a more general version of the model where all households face idiosyncratic preference shocks (see Wheaton 1990). Our results generalize to that version but there the equations are more cumbersome. We have chosen this simpler version to facilitate the presentation. In the current model, the only way for mismatched households become matched again is by purchasing an appropriate unit. In the more general version of the model, a mismatched household can become matched if it fails to purchase an appropriate unit but, because it is hit by a second preference shock, its valuation becomes high again (e.g. the household's job changes but, before its old residence is sold, the household is transferred back to the same area and no longer needs to move). It is worth noting that, in the data, households move every 10 years ( $\alpha$ is very low) while it takes only 8 weeks to buy a home on average, so these events we are neglecting have very low probability.

${ }^{11}$ Another reason why these households may want to buying a second home is that prices are rising so the unit can be sold at a higher price in the future. Note however that buyers may display a similar behavior: they may want to buy faster not only because they are mismatched but also because prices are rising. Since the environment is stationary, this kind of arbitrage is irrelevant in the steady state since prices are constant (though it would be relevant when analyzing the transitional dynamics).
} 
We plan to relax this assumption and check whether this insurance motive is quantitatively important (given that in the data households change dwellings every 10 years $-\alpha$ is very lowwe do not expect it to be).

Second, in terms of the timing, we assume that households who become mismatched first buy a new unit and then try to sell the old one. We have also considered a variant of the model with the reverse timing. There households first sell their old unit and then buy a new one, and in the interim while they do not own a unit they pay a cost in terms of rent or hotel fees (or a non-pecuniary cost of living with your parents/in-laws). While our qualitative results are identical in this variant, it is harder to match the targets in our calibration exercise (in terms of how often households change dwellings and how long it takes to sell a unit on average). ${ }^{12}$ This is why we have chosen the first timing.

\subsection{Competitive Search in the Housing Market}

Unlike in a centralized market where one can buy or sell a unit instantaneously at the market price, here sellers take time to find potential buyers and vice versa. In this section, we describe in detail the meeting process that brings buyers and sellers together in the housing market, as well as the price determination process. For simplicity, we drop all time subscripts since the process is the same every period.

We assume that house prices are determined by a competitive search process (see Montgomery 1991, Peters 1991, Moen 1997 and Shimer 1996, among others). That is, prior to the search process, sellers compete by simultaneously posting price offers (and committing to these offers). Buyers then observe all the posted offers and direct their search to the set of sellers posting the most attractive deal (possibly randomizing over offers if they are indifferent). All sellers who post an offer and all buyers who seek that offer form a submarket. In each submarket, buyers and sellers are then matched in bilateral pairs. When a buyer and a seller meet, the buyer inspects the unit and, if she likes it, she buys the unit at the posted price. Otherwise, there is no trade.

\footnotetext{
${ }^{12}$ One could allow agents to choose between the two timings. This should not alter the main predictions of the model, but it makes the analysis more complicated.
} 
We assume that in each submarket buyers and sellers experience at most one match each period. A standard matching function $\mathcal{M}: R_{+}^{2} \rightarrow R_{+}$determines the measure of bilateral matches as a function of the measures of buyers and sellers who participate in the submarket, which are denoted by $b$ and $s$ respectively. As usual, $\mathcal{M}(b, s)$ is increasing in both arguments, strictly concave, homogeneous of degree one, and continuously differentiable. Also, since the total number of matches cannot exceed the number of traders in the short side of the market, $\mathcal{M}(b, s) \leq \min \{b, s\}$. In particular, $\mathcal{M}(0, s)=\mathcal{M}(b, 0)=0$.

By the Law of Large Numbers, the probabilities with which buyers and sellers meet in each submarket depend on the ratio of buyers over sellers in that submarket (usually referred to as the degree of "congestion" or "market tightness"):

$$
\theta \equiv b / s
$$

Specifically, the probability that a seller meets a buyer in a submarket with a degree of congestion $\theta$ is

$$
m^{s}(\theta)=\frac{\mathcal{M}(b, s)}{s}=\mathcal{M}(\theta, 1)
$$

where $m^{s}: R_{+} \rightarrow[0,1)$ is strictly increasing, strictly concave and continuously differentiable, with $m^{s}(0)=0$ and $\lim _{\theta \rightarrow \infty} m^{s}(\theta)=1$. Intuitively, the higher the ratio of buyers over sellers the easier it is for sellers to meet buyers. As this ratio goes to infinity (zero) the probability that a seller meets a buyer goes to one (zero). Likewise, the probability that a buyer meets a seller is

$$
m^{b}(\theta)=\frac{\mathcal{M}(b, s)}{b}=\mathcal{M}\left(1, \theta^{-1}\right)=m^{s}(\theta) / \theta
$$

where $m^{b}: R_{+} \rightarrow[0,1)$ strictly decreasing and continuously differentiable, with $\lim _{\theta \rightarrow 0} m^{b}(\theta)=$ 1 and $\lim _{\theta \rightarrow \infty} m^{b}(\theta)=0$. In this case, the higher the ratio $\theta$ the harder it is for buyers to meet sellers. As this ratio goes to zero (infinity) the probability that a buyer meets a seller goes to one (zero).

It is useful to write $m^{s}(\theta)=m^{b}(\theta) \theta$. Also, we shall see below that the elasticity of the 
buyers' matching probability $m^{b}(\theta)$ :

$$
\eta(\theta)=\frac{-m^{b \prime}(\theta) \theta}{m^{b}(\theta)}
$$

will be a key parameter in the price determination process under competitive search. As is standard, we assume this elasticity is non-decreasing with $\eta(\theta) \in[0,1]$.

We shall assume that not all the units that buyers visit suit their needs. Specifically, we assume that in every random match between a buyer and a seller, the buyer's (per period) valuation for the seller's unit $v_{h}$ is a match-specific idiosyncratic random variable. This variable measures the quality of a match between the buyer and the unit, and is realized when the buyer visits the unit. For simplicity, we assume that $v_{h}$ is either 0 (the buyer does not like the unit) or $\bar{v}$ (the buyer likes the unit) with respective probabilities $q \in(0,1)$ and $1-q$. Intuitively, apart from characteristics which are easily verified over the phone or via e-mail (e.g. size, number of bedrooms/bathrooms, neighborhood, proximity to public transportation, year built, floor, ...), buyers' valuations usually depend on idiosyncratic features that can only be verified by visiting an inspecting the units. For instance, some buyers may be looking for a quiet unit (e.g. if they have trouble sleeping at night) and may want to check for sources of noise such as heavy traffic and loud neighbors, while other buyers may not care much about noise. Similarly, older households or households with limited mobility may want to avoid staircases, while younger households may not mind them much. Buyers will typically visit several units until they find one that suits their idiosyncratic needs/tastes. The lower the value of $q$, the larger the number of units buyers need to visit until they find one they like (the more "picky" they are). The parameter $q \in(0,1)$, together with the probability $\alpha$ of becoming mismatched, captures the extent of the matching frictions in the housing market.

Let us remark that, while we have assumed a general matching function, the urn-ball matching process is specially suitable for our environment and it is the one we use in our quantitative analysis. There $^{13}$

$$
m^{s}\left(\theta_{t}\right)=1-\exp \left\{-\theta_{t}\right\}, m^{b}\left(\theta_{t}\right)=\frac{1-\exp \left\{-\theta_{t}\right\}}{\theta_{t}}, \text { and } \eta\left(\theta_{t}\right)=\frac{\exp \left\{\theta_{t}\right\}-\left(1+\theta_{t}\right)}{\exp \left\{\theta_{t}\right\}-1}
$$

\footnotetext{
${ }^{13}$ Note that $\eta^{\prime}\left(\theta_{t}\right)>0, \lim _{\theta_{t} \rightarrow 0} \eta\left(\theta_{t}\right)=0$, and $\lim _{\theta_{t} \rightarrow \infty} \eta\left(\theta_{t}\right)=1$.
} 
Specifically, Peters (1991) constructs a game with a finite number of homogeneous buyers and sellers where sellers post offers to attract buyers and buyers cannot coordinate in choosing among these offers. He shows that as the number of traders gets large the symmetric equilibrium of the game generates this matching process endogenously (see also Burdett, Shi, and Wright 2001). ${ }^{14}$

\section{Search Equilibrium}

In this Section we characterize an equilibrium. First, we state the law of motion of the population distribution. Then we write down the value functions for non-traders, buyers and sellers. Finally, we describe how house prices are determined in a competitive search equilibrium.

The law of motion of the population distribution is as follows. Let $\pi_{t}^{s}$ denote the (endogenous) fraction of sellers who trade in period $t$. Given the composition of the population in period $t,\left\{n_{t}, b_{t}, s_{t}\right\}$, the measure of households who are matched with one unit in period $t+1$ is

$$
n_{t+1}=(1-\alpha) n_{t}+\pi_{t}^{s} s_{t}
$$

This includes those households who were matched with one unit in period $t$ continue to be matched at the start of $t+1$ (e.g. they are not hit by a shock). It also includes those sellers who sold their vacant unit in period $t .^{15}$

Similarly, let $\pi_{t}^{b}$ denote the fraction of buyers who trade in period $t$. The measure of buyers in period $t+1$ is

$$
b_{t+1}=\left(1-\pi_{t}^{b}\right) b_{t}+\alpha n_{t} .
$$

This includes those buyers who did not trade in period $t$, and continue to search for a unit

\footnotetext{
${ }^{14}$ In particular, the matching function in (7) describes how buyers' selection strategies respond to unilateral price deviations by sellers in the symmetric equilibrium as the number of agents gets large.

${ }^{15}$ For simplicity, we assume that former sellers leave the market for one period before they are hit by a shock again. This assumption is innocuous.
} 
in $t+1$. It also includes those households who were matched with one unit in period $t$ and become mismatched at the start of $t+1$ (e.g. they are hit by a shock).

We have already noted that the measure of sellers is constant when $H$ is fixed:

$$
s_{t+1}=\left(1-\pi_{t}^{s}\right) s_{t}+\pi_{t}^{b} b_{t}=H-N
$$

Those sellers who did not trade in period $t$ continue to be sellers in $t+1$. Those buyers who bought a unit in period $t$ and put up for sale their old unit in $t+1$ are also sellers in $t+1$.

Denote the values of buyers, sellers, and non-traders by $W_{t}^{b}, W_{t}^{s}$ and $W_{t}^{n}$, respectively. The values of buyers and sellers depend on the submarket where they participate in equilibrium. A submarket is characterized by a price $p_{t}$ and a ratio of buyers over sellers $\theta_{t}$. The Bellman equation of a buyer who participates in submarket $\left(p_{t}, \theta_{t}\right)$ is

$$
W_{t}^{b}=q m^{b}\left(\theta_{t}\right)\left[\max \left\{\bar{v}-p_{t}+\beta W_{t+1}^{s}, \underline{v}+\beta W_{t+1}^{b}\right\}\right]+\left(1-q m^{b}\left(\theta_{t}\right)\right)\left[\underline{v}+\beta W_{t+1}^{b}\right] .
$$

Buyers locate units with probability $m^{b}\left(\theta_{t}\right)$ which are suitable with probability $q$. If buyers choose to purchase these units, they get flow utility $\bar{v}$, pay a price $p_{t}$, and become sellers the following period. ${ }^{16}$ Otherwise, buyers get utility $\underline{v}$ from their current unit and continue to be buyers in period $t+1$.

The Bellman equation of a seller who participates in submarket $\left(p_{t}, \theta_{t}\right)$ is

$$
W_{t}^{s}=\bar{v}+q m^{b}\left(\theta_{t}\right) \theta_{t}\left[\max \left\{p_{t}+\beta W_{t+1}^{n}, \beta W_{t+1}^{s}\right\}\right]+\beta\left(1-q m^{b}\left(\theta_{t}\right) \theta_{t}\right) W_{t+1}^{s} .
$$

Sellers always get flow utility $\bar{v}$ from the unit where they reside, whether or not they trade. If they meet a buyer who likes their vacant unit and sell the unit, they receive the price $p_{t}$ and exit the housing market the following period. Otherwise, they continue to be sellers in $t+1$.

\footnotetext{
${ }^{16}$ We shall see that, if the buyer wants to trade, so will the seller (and vice versa). The reason is that in equilibrium both parties receive a positive share of the bilateral surplus, so both will choose to trade as long as the bilateral surplus is positive (and will choose not to trade otherwise).
} 
Finally, the Bellman equation of a non-trader is

$$
W_{t}^{n}=\bar{v}+\beta\left[(1-\alpha) W_{t+1}^{n}+\alpha W_{t+1}^{b}\right]
$$

Non-traders get flow utility $\bar{v}$ for their only unit and do not participate in the housing market in period $t$. However, with probability $\alpha$ they become mismatched at the start of period $t+1$ and seek to buy a unit during that period.

The Bellman equations (11)-(13) can be reexpressed as

$$
\begin{aligned}
W_{t}^{b} & =\underline{v}+\beta W_{t+1}^{b}+\max \left\{S_{t}^{b}\left(\theta_{t}, p_{t}\right), 0\right\} \\
W_{t}^{s} & =\bar{v}+\beta W_{t+1}^{s}+\max \left\{S_{t}^{s}\left(\theta_{t}, p_{t}\right), 0\right\}, \\
W_{t}^{n} & =\bar{v}+\beta W_{t+1}^{n}-\beta \alpha\left(W_{t+1}^{n}-W_{t+1}^{b}\right),
\end{aligned}
$$

where $S_{t}^{b}\left(\theta_{t}, p_{t}\right)$ and $S_{t}^{s}\left(\theta_{t}, p_{t}\right)$ represent the expected trade surpluses for buyers and sellers in the submarket $\left(\theta_{t}, p_{t}\right)$ where they choose to trade in period $t$ :

$$
\begin{aligned}
& S_{t}^{b}\left(\theta_{t}, p_{t}\right)=q m^{b}\left(\theta_{t}\right)\left[\bar{v}-\underline{v}-p_{t}+\beta\left(W_{t+1}^{s}-W_{t+1}^{b}\right)\right] \\
& S_{t}^{s}\left(\theta_{t}, p_{t}\right)=q m^{b}\left(\theta_{t}\right) \theta_{t}\left[p_{t}+\beta\left(W_{t+1}^{n}-W_{t+1}^{s}\right)\right]
\end{aligned}
$$

When they trade, buyers get an increase $\bar{v}-\underline{v}$ in their current flow utility and pay the price $p_{t}$. Because they become sellers in period $t+1$ their continuation utility also changes. Similarly, when sellers trade, they receive the price $p_{t}$ and they exit the market in period $t+1$ (as a result of which their continuation value changes).

The expressions of the expected trade surpluses in equations (17) and (18) highlight the fact that, in the presence of search frictions, traders care not only about prices but also about the expected time it takes then to trade. ${ }^{17}$ Buyers prefer low prices and low buying times (low congestion), while sellers prefer high prices and low selling times (high congestion). This trade-off between prices and trading delays is key in the division of the surplus between buyers and sellers under competitive search (see, for instance, Peters 1991 and Moen 1997).

The bilateral surplus is the sum of the ex-post surplus of the buyer and the seller (when

\footnotetext{
${ }^{17}$ And how their continuation values change when they trade.
} 
the buyer likes the unit): ${ }^{18}$

$$
S_{t}=\bar{v}-\underline{v}+\beta(1-\alpha)\left(W_{t+1}^{n}-W_{t+1}^{b}\right) .
$$

This surplus includes the instantaneous gain from a match, $\bar{v}-\underline{v}$, as well as the gain in terms of the expected change in the discounted continuation utilities of buyers and sellers, $\beta(1-\alpha)\left(W_{t+1}^{n}-W_{t+1}^{b}\right)$ (i.e., when agents trade the buyer becomes a seller and the seller becomes a no-trader).

The key to the competitive search process is that all traders have rational expectations about the number of buyers that will be attracted by price posted by sellers, and hence about the degree of congestion the offer will generate. In a competitive search equilibrium the offers posted by sellers must be such that no seller has an incentive to post a deviating offer.

Let $\Omega_{t}$ denote the set of all submarkets that are active in equilibrium in period $t$. In a competitive search equilibrium the following must hold. First, since all buyers are symmetric and are free to choose the submarket they visit, they must receive a common expected surplus: $S_{t}^{b}\left(\theta_{t}, p_{t}\right)=\bar{S}_{t}^{b}$ for all $\left(\theta_{t}, p_{t}\right) \in \Omega_{t}$. Similarly for sellers: $S_{t}^{s}\left(\theta_{t}, p_{t}\right)=\bar{S}_{t}^{s}$ for all $\left(\theta_{t}, p_{t}\right) \in \Omega_{t}$. Finally, each $\left(\theta_{t}, p_{t}\right) \in \Omega_{t}$ must solve the following program:

$$
\bar{S}_{t}^{s}=\max _{\left(\theta_{t}, p_{t}\right) \in R_{+} \times R} S^{s}\left(\theta_{t}, p_{t}\right) \text { s.t. } \bar{S}_{t}^{b}=S^{b}\left(\theta_{t}, p_{t}\right)
$$

In words, any posted price $p_{t}$ and associated congestion $\theta_{t}$ must maximize the expected surplus of the sellers while ensuring that buyers get their common expected surplus. This means that the equilibrium outcome must lie in the contract curve, so it is constrained efficient.

The last condition is intuitive. Sellers cannot gain by posting deviating price offers. If a small mass of sellers deviates and posts a different offer $p_{t}^{\prime}$ that attracts buyers, that offer cannot yield more than $\bar{S}_{t}^{b}$ (otherwise, other sellers would profitably undercut this offer). Given the common utility received by buyers $\bar{S}_{t}^{b}$, any deviating offer $p_{t}^{\prime}$ would then attract $\theta_{t}^{\prime}$ buyers per seller, where $\bar{S}_{t}^{b}=S^{b}\left(\theta_{t}^{\prime}, p_{t}^{\prime}\right)$. That is, buyers will switch to this offer $p_{t}^{\prime}$ until

\footnotetext{
${ }^{18}$ We assume that when the buyer does not like the unit, there is no trade.
} 
they are indifferent between trading with the deviating sellers and trading with the nondeviating sellers (and getting $\bar{S}_{t}^{b}$ ). It follows that sellers cannot gain by posting deviating offers if and only if the equilibrium values of $\theta_{t}, p_{t}$ solve program (20).

It is easy to check that the solution $\left(\theta_{t}, p_{t}\right)$ of this convex program is unique and interior for given $\bar{S}_{t}^{b}, \bar{S}_{t}^{s}>0 .{ }^{19}$ This means that, if there is trade, all units are traded at the same price and with identical probability. In other words, a unique submarket will be active in equilibrium. The solution is characterized by the following tangency condition:

$$
\frac{\frac{\partial S^{b}\left(\theta_{t}, p_{t}\right)}{\partial \theta_{t}}}{\frac{\partial S^{b}\left(\theta_{t}, p_{t}\right)}{\partial p_{t}}}=\frac{\frac{\partial S^{s}\left(\theta_{t}, p_{t}\right)}{\partial \theta_{t}}}{\frac{\partial S^{s}\left(\theta_{t}, p_{t}\right)}{\partial p_{t}}}
$$

Differentiating (17) and (18), substituting into (21), and using equations (23) and (24), we obtain

$$
\frac{\bar{v}-\underline{v}-p_{t}+\beta\left(W_{t+1}^{s}-W_{t+1}^{b}\right)}{p_{t}+\beta\left(W_{t+1}^{n}-W_{t+1}^{s}\right)}=\frac{1-\eta\left(\theta_{t}\right)}{\eta\left(\theta_{t}\right)} .
$$

That is, if there is trade in period $t$, the equilibrium price $p_{t}$ is determined by the bargaining rule in Hosios (1990) where sellers get a share $\eta\left(\theta_{t}\right)$ of the bilateral surplus and buyers get a share $1-\eta\left(\theta_{t}\right)$. This in turn implies that, as long as $S_{t}$ is positive, there will be trade in equilibrium since buyers and sellers get a positive share of this surplus. Therefore,

$$
\begin{aligned}
& \pi_{t}^{b}=\left\{\begin{array}{cc}
m^{b}\left(\theta_{t}\right) q & \text { if } S_{t} \geq 0 \\
0 & \text { if } S_{t}<0
\end{array}\right. \text { and } \\
& \pi_{t}^{s}=\left\{\begin{array}{cc}
m^{b}\left(\theta_{t}\right) \theta q & \text { if } S_{t} \geq 0 \\
0 & \text { if } S_{t}<0
\end{array}\right. \text { and }
\end{aligned}
$$

where $\theta_{t}=b_{t} / s_{t}$ is the economy-wide ratio of buyers and sellers.

We are now ready to define a symmetric search equilibrium.

\footnotetext{
${ }^{19}$ Substituting $p$ as a function of $\theta$ from the constraint into the objective function yields an strictly concave function (because $m^{s}(\theta)$ is strictly concave). Also, because $\bar{S}^{i s}, \bar{S}^{i b}>0$, the unique solution must satisfy $0<\theta<\infty$.
} 
Definition 1: A search equilibrium is a set

$$
\left\{n_{t}, b_{t}, s_{t}, p_{t}, \theta_{t}, \pi_{t}^{b}, \pi_{t}^{s}, W_{t}^{b}, W_{t}^{s}, W_{t}^{n}, S^{t}, S_{t}^{b}, S_{t}^{s}\right\}_{t=0}^{\infty}
$$

that satisfies the system of equations (1), (2), time-indexed versions of (3) and (23)-(6), (8), and (14)-(22), given an initial population distribution $\left(n_{0}, b_{0}, H-N\right)$.

A couple of remarks are useful at this point.

Remark 1: It is straightforward to write the Nash bargaining version of the model. Simply replace the competitive search pricing equation (22) by its Nash bargaining counterpart:

$$
\frac{\bar{v}-\underline{v}-p_{t}+\beta\left(W_{t+1}^{s}-W_{t+1}^{b}\right)}{p_{t}+\beta\left(W_{t+1}^{n}-W_{t+1}^{s}\right)}=\frac{1-\eta}{\eta},
$$

where $\eta$ denotes the sellers' Nash bargaining weight and $1-\eta$ denotes the buyers' Nash bargaining weight.

Remark 2: It is direct to extend the benchmark model to allow for taxes or intermediation costs. Suppose buyers and sellers had to pay an extra cost to trade, $F^{b}$ and $F^{s}$ (where $F^{b}+F^{s}$ does not exceed the bilateral surplus). For instance, these costs could be proportional to the price and/or include a fixed part: $F^{i}=\left(1+f^{i}\right) p_{t}+\bar{F}^{i}, i=b, s$. In this case, the expressions of the surpluses (17)-(18) should be modified to reflect the fact that the price paid by buyers $p_{t}^{b}$ is different from the price $p_{t}^{s}$ received by sellers: $p_{t}^{b}=p_{t}+F^{b}, p_{t}^{s}=p_{t}-F^{s}$. The equilibrium will then be characterized as above except that now the pricing equation (22) is replaced by

$$
\frac{\bar{v}-\underline{v}-p_{t}-F^{b}+\beta\left(W_{t+1}^{s}-W_{t+1}^{b}\right)}{p_{t}-F^{s}+\beta\left(W_{t+1}^{n}-W_{t+1}^{s}\right)}=\frac{1-\eta\left(\theta_{t}\right)}{\eta\left(\theta_{t}\right)}
$$

and the bilateral surplus in (27) now becomes

$$
S_{t}=\bar{v}-\underline{v}+\beta(1-\alpha)\left(W_{t+1}^{n}-W_{t+1}^{b}\right)-F^{b}-F^{s}
$$




\subsection{Steady State}

Consider the interesting case where the bilateral surplus is positive. The steady state is characterized by the following system of equations

$$
\begin{aligned}
N & =n+b+s \\
s & =H-N, \\
b & =\theta s, \\
\alpha n & =m^{b}(\theta) \theta q s, \\
(1-\beta) W^{b} & =\underline{v}+m^{b}(\theta) q\left[\bar{v}-\underline{v}-p+\beta\left(W^{s}-W^{b}\right)\right], \\
(1-\beta) W^{s} & =\bar{v}+m^{b}(\theta) \theta q\left[p+\beta\left(W^{n}-W^{s}\right)\right], \\
(1-\beta) W^{n} & =\bar{v}-\beta \alpha\left(W^{n}-W^{b}\right), \\
\frac{\bar{v}-\underline{v}-p+\beta\left(W^{s}-W^{b}\right)}{p+\beta\left(W^{n}-W^{s}\right)} & =\frac{1-\eta(\theta)}{\eta(\theta)}, \\
\eta(\theta) & =\frac{-m^{b \prime}(\theta) \theta}{m^{b}(\theta)} .
\end{aligned}
$$

Equation (31) is perhaps the only one that is not self-explanatory. This equation ensures that the flows in and out of the non-trading state are equal. A fraction $\alpha$ of households flows out of this state each period, while households flowing into this state are sellers who successfully sell their vacant unit.

Since $s=H-N$, from (28)-(30) we obtain $b$ and $n$ as a function of $\theta$ :

$$
\begin{aligned}
b & =\theta(H-N) \\
n & =2 N-H-\theta(H-N) .
\end{aligned}
$$

Using (31), $\theta$ is then given by

$$
\alpha\left(\frac{2 N-H}{H-N}-\theta\right)=m^{b}(\theta) \theta q .
$$


Denoting the vacancy rate by $V=1-N / H$, we may rewrite (39) as

$$
\alpha\left(\frac{1}{V}-2-\theta\right)=m^{b}(\theta) \theta q
$$

where $V \in(0,1 / 2)$ since $H \in(N, 2 N)$. This is a key equation which yields $\theta$ as a function of $V, \alpha, q$, and $m^{b}($.$) . In particular, it both intuitive and direct to see that the number of$ buyers per seller $\theta$ increases with $\alpha$ and decreases with $V$ and $q .{ }^{20}$

Given $\theta$, we may obtain $p, W^{b}, W^{s}$ and $W^{n}$ (and the surpluses $S^{b}, S^{s}$ and $S$ ) using (32)(36). For instance, manipulating these equations one can express house prices as a function of $\theta$ and $S$ :

$$
p=\frac{1}{1-\beta}(\bar{v}-\underline{v})+S\left[\frac{\beta}{1-\beta} m^{b}(\theta) q[(1+\theta) \eta(\theta)-1]-1+\eta(\theta)\right] .
$$

The bilateral surplus $S$ can in turn be written as

$$
\begin{aligned}
S & =\bar{v}-\underline{v}+\beta(1-\alpha)\left(W_{n}-W_{b}\right) \text { where } \\
W_{n}-W_{b} & =\frac{(\bar{v}-\underline{v})\left[1-m^{b}(\theta) q(1-\eta(\theta))\right]}{\left.1-\beta(1-\alpha)+\beta m^{b}(\theta) q(1-\eta(\theta))\right]}>0 .
\end{aligned}
$$

Remember that, when buyers and sellers trade, the net gain in terms of the change in the discounted values is $\beta(1-\alpha)\left(W_{n}-W_{b}\right)$. Equation (43) shows that this gain is always positive. Hence the bilateral surplus is positive in a steady state (as we have assumed). The equilibrium values $W^{n}, W^{b}$ and $W^{s}$ can also be expressed as a function of $W_{n}-W_{b}$ :

$$
\begin{aligned}
W^{n} & =\frac{\bar{v}-\beta \alpha\left(W_{n}-W_{b}\right)}{1-\beta} \\
W^{b} & =\frac{\underline{v}+m^{b}(\theta) q(1-\eta(\theta))\left[\bar{v}-\underline{v}+\beta\left(W_{n}-W_{b}\right)\right]}{1-\beta} \\
W^{s} & =\frac{\bar{v}+m^{b}(\theta) \theta q \eta(\theta)\left[\bar{v}-\underline{v}+\beta\left(W_{n}-W_{b}\right)\right]}{1-\beta}
\end{aligned}
$$

It is easy to check that both $W_{n}-W_{b}$ and $S$ increase with $\theta$ (other things equal). This is intuitive. When $\theta$ is higher, it takes more time to buy a unit. This increases the loss from experiencing a preference shock when matched (measured by $W_{n}-W_{b}$ ), and hence the gains

\footnotetext{
${ }^{20}$ Remember that $m^{b}(\theta) \theta$ is increasing in $\theta$.
} 
from bilateral trade. It is also easy to check that $W^{s}$ increases with $\theta$. Intuitively, the value of being a seller increases when there are relatively more buyers because average time on the market falls and the seller's ex-post trade surplus is also higher (since the total surplus $S$ is higher and the share $\eta(\theta)$ sellers receive is also higher). By contrast, $W^{n}$ and $W^{b}$ fall with $\theta$. The value of being a buyer decreases because it takes longer on average to buy a unit and (even though the total bilateral surplus is higher) the buyers' share of the surplus is lower. The value of non-traders falls because, in the event they become mismatched buyers, their value will be lower. The effect on the price $p$ of changes in $\theta$ is ambiguous in general.

Our simple equilibrium characterization allows us to derive steady-state comparative static results.

Proposition 1. Changes in the vacancy rate (e.g. due to changes in the housing stock or in the population) have the following effects on a steady-state equilibrium:

$$
\begin{aligned}
& \frac{\partial \theta}{\partial V}<0 ; \frac{\partial \pi^{s}}{\partial V}<0 ; \frac{\partial \pi^{b}}{\partial V}>0 ; \\
& \frac{\partial(s / N)}{\partial V}>0 ; \frac{\partial(b / N)}{\partial V}<0 ; \quad \frac{\partial n}{\partial V}<0 \text { if } \theta_{s}<\theta, \frac{\partial(n / N)}{\partial V}>0 \text { if } \theta>\theta_{s} ; \\
& \frac{\partial\left(\pi^{s} V\right)}{\partial V}<0 \text { if } \theta_{s}<\theta, \frac{\partial\left(\pi^{s} V\right)}{\partial V}>0 \text { if } \theta>\theta_{s} ; \\
& \frac{\partial S}{\partial V}<0 ; \text { and } \frac{\partial p}{\partial V}<0 \text { if } \theta>\theta_{p} \text { (otherwise the effect on } p \text { is ambiguous). }
\end{aligned}
$$

Here $\theta_{s}$ and $\theta_{p}$ are threshold values which satisfy $\theta_{s}>\theta_{p}$ if $\beta$ is not too low.

When the vacancy rate increases (e.g. the housing stock $H$ is higher relative to the population) the ratio $\theta$ of buyers over sellers falls (from (40)). This increases average time on the market and decreases the time it takes to buy ( $\pi^{s}$ falls and $\pi^{b}$ increases). The fraction of households who are sellers then increases while the fraction of buyers falls. Since it is easier to purchase a unit, the loss of being mismatched falls and so does the total bilateral surplus. The effect on sales (as a fraction of the stock) is ambiguous because, while there are relatively more units for sale, they take longer to sell. The effect on sales is positive when $\theta$ exceeds a certain threshold, $\theta_{s}$. Below this threshold, however, the number of buyers per sellers is already low so when $\theta$ falls, the decrease in average time on the market out-weights the increase in the number of units for sale, and sales fall as a result. The sign of the effect 
on the fraction of non-traders is the same as that of sales (e.g. it is negative for $\theta<\theta_{s}$ so fewer agents are matched with one unit). Prices decrease if $\theta$ is above a certain threshold $\theta_{p}$ (but below this threshold the price effect is ambiguous). Finally, provided $\beta$ is not too low $\theta_{p}<\theta_{s}$, so prices and volume co-move for $\theta \in\left(\theta_{p}, \theta_{s}\right)$. This will be the relevant range in our calibration exercise as we shall see.

Proposition 2. Changes in the probability $\alpha$ of becoming mismatched have the following effects on a steady-state equilibrium:

$$
\frac{\partial \theta}{\partial \alpha}>0, \frac{\partial \pi^{s}}{\partial \alpha}>0, \frac{\partial \pi^{b}}{\partial \alpha}<0, \frac{\partial b}{\partial \alpha}>0, \frac{\partial s}{\partial \alpha}=0, \frac{\partial n}{\partial \alpha}<0, \text { and } \frac{\partial\left(\pi^{s} V\right)}{\partial \alpha}>0 .
$$

The effects on $p$ and $S$ are ambiguous in general.

An increase in the rate at which households become mismatched each period (e.g. greater job mobility or younger population) increases the number of buyers per seller in a steady state. This decreases average time on the market and increases sales (as a fraction of the stock). The time it takes to buy a unit increases and so does the number of buyers. The number of sellers remains constant, and the number of non-traders falls. In general the effect on the price and the bilateral surplus is ambiguous. Yet, in our calibration exercise both effects are positive for parameter values which are consistent with our targets (e.g. how long it takes to buy a unit and how often households change dwellings on average). Therefore, for reasonable parameter values prices and sales will again co-move and will be negatively correlated with time on the market.

Proposition 3. Changes in the probability $q$ that a buyer likes a unit visited at random have the following effects on a steady-state equilibrium:

$$
\frac{\partial \theta}{\partial q}<0 ; \frac{\partial \pi^{s}}{\partial q}>0 ; \frac{\partial \pi^{b}}{\partial q}>0 ; \frac{\partial b}{\partial q}<0 ; \frac{\partial s}{\partial q}=0 ; \frac{\partial n}{\partial q}>0 ; \frac{\partial\left(\pi^{s} V\right)}{\partial q}>0 ; \frac{\partial S}{\partial q}<0 .
$$

The effect on $p$ is ambiguous.

When $q$ increases, it becomes easier for buyers to find and purchase a unit they like. Such a change could reflect for instance an improvement in the intermediation technology (e.g. through new channels like the internet). It could also reflect (in an ad-hoc way) better 
access to credit. An increase in $q$ reduces the number of buyer per seller in the market in the steady state. While the probability that a potential buyer likes the house is higher, sellers are now less likely to find a buyer. It is easy to check that the first effect dominates and average time on the market decreases and sales increase. Also, the number of non-traders increases and the number of buyers falls. The total bilateral surplus decreases because the loss from being mismatched is now lower. The effect on the price is ambiguous in general, and it is hump-shaped our calibration exercise (increasing for low values of $q$ and decreasing above a certain threshold).

Finally, changes in the households' flow utilities do not affect neither sales nor time on the market because they do not affect $\theta$ (see (39)). These changes are only affect prices. This is so because the stock of houses is given.

\section{A quantitative exercise}

\subsection{Calibration of the model economy}

In this section we conduct several quantitative exercises to check the ability of the search model to account for the observed co-movements of the price, sales and time on the market. First of all, we need to calibrate our model economy.

We assume that the model period is a week. The discount factor $\beta$, in annual terms is set equal to 0.96. We calibrate the model economy to account for the following set of observations: according to the U.S. Housing Vacancy Survey the average quarterly vacancy rate for the period 1985-2001 was about 1.5 percent. The National Association of Realtors conducts an annual survey, the Profile of Home Buyers and Sellers. There it is reported that buyers typically search for 8 weeks and that they plan to stay in their home for about 10 years. We use these three observations to calibrate $q$ and $\alpha$. In the model, the average number of weeks it takes to buy a unit is $1 / \pi_{b}(\theta)$. Moreover, after some calculations it can be shown that average tenure length is $(1-\alpha) / \alpha+1 / \pi_{b}(\theta)$ periods. We use the matching function in Peters (1991), so $\pi_{b}(\theta)=q \frac{1-\exp \{-\theta\}}{\theta}$ (see equation (6)). With these observations, we find that $H / N=1.0152, q=0.1972$, and $\alpha=0.0019$. Since we do not have any guidance 
to set values for the utility of being matched and mismatched, we assume that $\underline{v}=0.1$ and $\bar{v}=1$. This implies that the household's discounted utility of being matched (mismatched) through its lifetime is $\bar{v} /(1-\beta)=1274.32(\underline{v} /(1-\beta)=127.43$ respectively). The targets of our calibration are shown in Table 1.

At the steady state, we find that $\theta=0.993$. That is, the numbers of buyers and sellers are very similar (because $\alpha$ is pretty low) but sellers lie on the long side of the market. This in turn implies that it takes 8.05 weeks on average to sell a unit. It may be argued that this figure is too low-i.e., it takes very few weeks to sell a unit in our model economy. The way we interpret this result is that we are imposing a minimal amount of search frictions so that, quantitatively, the steady state is very close to that of the version of the Walrasian model economy (see Section 5). The equilibrium price is 814.57 . This price is such that the seller gets 41.56 percent of the bilateral match surplus in a transaction. The bilateral surplus each period is 11.91 .

Now we turn to study the quantitative effect of changes in various parameters. Our objective is to study the responsiveness of the price, sales, time on the market to such changes.

\subsection{Across steady state comparisons}

\subsubsection{Changes in the vacancy rate}

In our first exercise, we study the steady state effects of an increase in the vacancy rate (e.g. an increase in the housing stock or a decrease in the population size). As stated in Proposition 1, Figures 1 and 2 show that the market tightness $\theta$ falls, and so do the aggregate surplus and the seller's surplus. Sales as a fraction of the housing stock fall. The price falls sharply. For instance, Table 3 shows the steady state effects of a change in the vacancy rate going from 1.5 percent to 4 percent. Notice that the price falls dramatically from 814.57 to 52.23. Intuitively, prices fall not only because the surplus is lower but also because seller's loose bargaining power (their share falls from $41.56 \%$ to $12.12 \%$ ). Sales as a fraction of the stock fall from $0.186 \%$ to $0.176 \%$. Time on the market, the mean time to sell, increases from 8 weeks to 22.67 weeks (about 5.5 months). 


\subsubsection{Changes in home tenure length}

Next, we turn to examine the effect of changes in the probability $\alpha$ of becoming mismatched. These changes could be interpreted as changes in the degree of geographical mobility. A change in $\alpha$ could also reflect a change in age of the typical buyer. For instance, the Profile of Home Buyers and Sellers reports that younger households expect a tenure length of 7 years, whereas older households expect to stay in the same unit for about 12 years. We could interpret an economy where $\alpha$ is low as an economy with relatively old population, whereas in an economy where all agents are very young should correspond in our framework with an economy with large $\alpha$. In Figures 3 and 4 we have plotted the steady state for different values of $\alpha$. The lowest value of $\alpha$ implies that households are hit by the mobility shock every 20 years, on average. The highest value of $\alpha$ implies that households become mismatched every 6 years. Again the vacancy rate is 1.5 percent. As shown in Proposition 2, as $\alpha$ increases, sales increase and time on the market falls. Prices also increase. Hence, the greater the degree of mobility, the "hotter" the market and the higher the liquidity of housing assets. As we have already noted, a larger $\alpha$ implies a larger number of buyers. This increases the price, the volume of sales and lowers the time it takes to sell a house. Table 4 shows the steady state effects when the expected tenure length falls from 10 years to 7 years. Notice the wild increase in the price: from 814.57 in the benchmark to 6469.3, a factor of almost 7. Again prices rise not only because the bilateral surplus higher but also because sellers gain bargaining power (their share increases from $41.56 \%$ to $73.96 \%$ ). Sales as a fraction of the stock increase from $0.186 \%$ to $0.265 \%$. Time on the market, the mean time to sell, falls from 8 weeks to 5.652 weeks.

\subsubsection{Changes in the informational friction parameter $q$}

We also assess the effect of the probability $q$ that a buyer likes a unit visited at random (e.g. the extent of matching frictions). As we have already noted, we could think of $q$ as a parameter capturing informational frictions about the suitability of the house found by the buyer. Figures 5 and 6 show the steady state for different values of $q$, again for a vacancy rate of 1.5 percent. As noted in Proposition 3, time on the market falls with $q$, and sales increase. As we can see, the price has a non-monotonic behavior. This is so because $q$ affects 
both the effective demand and supply of houses. For very low values of $q$, the market is frozen because it is very hard to find an appropriate unit. The effective demand of houses increases with $q$ (as buyers locate appropriate units faster). This in turn increases the price. After some threshold level, a larger $q$ implies that the supply of houses suitable for any given buyer increases. Hence, the price must decrease.

\subsubsection{Changes in the value of being matched $\bar{v}$}

Finally, we have included an exercise where the value $\bar{v}$ of being matched increases. Our analysis shows that $\theta$ is independent of households' valuations, so that the only variable affected is the price. This is reflected in Figure 7. Actually, changes in $\bar{v}$ translate almost in a one-to-one basis to the price.

\section{$5 \quad$ Frictionless Walrasian Economy}

It is illustrative to consider at this point the limiting perfectly competitive situation where search frictions vanish. In this case, buyers can perfectly identify suitable units so $q=1$, and matching is frictionless so

$$
\mathcal{M}\left(b_{t}, s_{t}\right)=\min \left\{b_{t}, s_{t}\right\}, \quad m^{s}\left(\theta_{t}\right)=\min \left\{\theta_{t}, 1\right\}, \quad m^{b}\left(\theta_{t}\right)=\min \left\{1, \theta_{t}^{-1}\right\} .
$$

In words, traders on the short side of the market trade with probability one. For markets to clear, traders on the long side of the market are must be indifferent between trading or not. This means that, in this frictionless world with homogeneous buyers and sellers, competitive prices are such that the entire bilateral surplus goes to the traders on the short side of the market (while trades on the short side of the market get zero surplus). The equilibrium is defined as before, except that now the trading probabilities are those in (47), and the pricing equation $p_{t}$ is different (equation (22) does not apply).

Consider first the case where $\theta_{t}<1$. Since there are fewer buyers than sellers $\pi^{b}\left(\theta_{t}\right)=$ $m^{b}\left(\theta_{t}\right)=1$ and $\pi^{s}\left(\theta_{t}\right)=m^{s}\left(\theta_{t}\right)=\theta$. Moreover, buyers get all the surplus in this case: $S_{t}^{b}=S_{t}$ and $S_{t}^{s}=0$. It is direct to check that the competitive price is $p_{t}=\beta\left(W_{t+1}^{s}-W_{t+1}^{n}\right)$. If $\theta_{t}>1$, 
there are more buyers than sellers so $\pi^{s}\left(\theta_{t}\right)=m^{s}\left(\theta_{t}\right)=1$ and $\pi^{b}\left(\theta_{t}\right)=m^{b}\left(\theta_{t}\right)=\theta^{-1}$. Also, the entire surplus goes to the sellers now: $S_{t}^{s}=S_{t}$ and $S_{t}^{b}=0$. The competitive price in this case is $p_{t}=\bar{v}-\underline{v}+\beta\left(W_{t+1}^{s}-W_{t+1}^{b}\right)$.

We may again characterize the steady state and derive comparative static results. Below we describe the effects of changes in the vacancy rate $V$ and the probability $\alpha$ of becoming mismatched since these were the key variables for the results in Section 3.1. ${ }^{21}$

For the case where $\theta>1$ in the steady state, the next propositions describe the effects on the equilibrium outcome of changes in $V$ and $\alpha$ (which are small so it is still the case that $\theta>1$ after the change).

Proposition 4. Let us restrict to $\theta>1$. When $V$ increases, $\pi_{s}(\theta)=1$ is constant, $\theta$ falls and $\pi_{b}(\theta)$ increases. Also, $\pi_{s}(\theta) V$ increases, while $S$ and $p$ remain constant.

In a Walrasian equilibrium, time to sell does not respond to demand changes when sellers are on the short side of the market. Sales as a fraction of the stock increase because the vacancy rate increases, but prices do not change either. On the other hand, an increase in the probability $\alpha$ of becoming mismatched does not affect neither sales nor time on the market. It only decreases the surplus and thus the price sellers get.

Proposition 5. Let us restrict to $\theta>1$. When $\alpha$ increases, $\pi_{s}(\theta)=1$ is constant, $\theta$ increases and $\pi_{b}(\theta)$ falls. Also, $S$ and $p$ fall, while $\pi_{s}(\theta) V$ remains constant.

We now turn to the case where $\theta<1$. The following propositions show that in this case, both time to sell and sales respond to demand changes, but prices remain constant.

Proposition 6. Let us restrict to $\theta<1$. When $V$ increases, $\pi_{b}(\theta)=1$ is constant, $\theta$ and $\pi_{s}(\theta)$ fall. Also, $\pi_{s}(\theta) V$ fall, while $S$ and $p$ remain constant. When $\alpha$ increases, $\pi_{b}(\theta)=1$ is constant, $\theta$ and $\pi_{s}(\theta)$ increase. Also, $\pi_{s}(\theta) V$ increase, while $S$ and $p$ remain constant.

We conclude that, unlike in the search model, for prices to react (jointly with sales) to exogenous demand changes $\theta$ must be switching from values above 1 to values below 1 in

\footnotetext{
${ }^{21}$ These effects are identical if $q<1$ (i.e., even if buyers identify a suitable unit with probability less than one each period, and once they do the unit is traded in a Walrasian market).
} 
the Walrasian model. This is intuitive since the search model can be thought as a "smooth" version of the Walrasian model. In the Walrasian model, there is a stark discontinuity as the sellers' share of the surplus jumps from 1 to 0 when $\theta$ moves from values above 1 to values below 1 but does not change otherwise. In the competitive search model instead, this share changes continuously with $\theta$ and as we have seen, with the exponential matching function in Peters (1991), its reaction is quite stark to changes in $\theta$. To illustrate this idea we have computed the Walrasian version of our benchmark economy and we have simulated its steady state for various levels of the vacancy rate. Figures 8 and 9 show the steady state values associated to vacancy rates between 1 and 5 percent. As we can see in Figure 8 market tightness, $\theta$, is always higher in the economy with search frictions than its Walrasian counterpart. This is so because of the search friction. Notice also that the price decreases with the vacancy rate in the search economy whereas is constant, and significantly lower, in its Walrasian counterpart. This is so because the Walrasian price is always equal to the seller's reservation price, since sellers are the long side of the market. Thus, as it is shown in Figure 9 sellers' share of the surplus in the Walrasian economy is zero. Interestingly, the Walrasian aggregate surplus is positive and very low, almost zero. This is so because buyers' utility is very close to that of non traders, since the cost of being mismatched one period is not so high. Finally, notice that sales fall with vacancy rate, as shown in Figure 8, either for the search economy and its Walrasian counterpart. This is a direct result of having more vacant houses.

Next, we have conducted the same exercise but assuming that the vacancy rate changes from 0.1 percent to 1.5 percent. The results are shown in Figures 10 and 11. Notice that the Walrasian price jumps from being equal to the buyer's reservation price to the seller's reservation price. Hence it is possible to have significant fluctuations in prices a Walrasian economy, but it requires a very tiny vacancy rate, much smaller than what is observed in the data. Moreover, while prices fall, sales increase. We conclude that the search model is consistent with the co-movement of prices and sales and the stark reaction of prices to demand changes we see in the data, while its Walrasian version is not. 


\section{Discussion of the results and final comments}

In this paper we have studied house price formation in a model economy with search frictions. Our goal was to build a simple framework where prices and volume of sales are positively correlated, and both variables are negatively related with time to sell as in the data. The fact that time to sell changes substantially over time in the data is indicative of the existence of frictions that cannot be accommodated in a Walrasian framework. This is why we moved to a model economy with search frictions.

We have made several choices in this paper that may render our model economy too stylized. We think of this as a virtue of our model economy, since it shows clearly the forces underlying our results. The first lesson we have learnt is that the search model is consistent with the co-movement of prices and sales and their negative correlation with time on the market, while its Walrasian counterpart is not.

Next we have calibrated our model economy to match selected statistics of the U.S. economy and conducted various quantitative exercises. For instance, we have seen that an increase in the housing vacancy rate from 1.5 percent to 4 percent implies a reduction in the equilibrium price by a factor of 16 . This is a wild change in the price. When we calibrate the Walrasian version of our model economy, the equilibrium price does not move.

We have assumed homogeneous buyers and sellers for the sake of simplicity. If buyers and/or sellers were heterogeneous, the results would not be so extreme: the Walrasian price could change. But the price in the search world would also change due to this added heterogeneity. Thus, we think that our results should still hold: the price of the search framework should move significantly with respect to its Walrasian counterpart. We think that it is a virtue of the model that it can deliver the results in the simplest benchmark without heterogeneity.

There are three factors affecting the quantitative behavior of prices in the search model. First, search frictions themselves but, secondly, how search frictions are modeled. We have chosen a competitive notion of equilibrium for search environments, and the matching function derived by Peters (1991) for these kinds of environments when buyers and sellers are homogeneous (i.e., with rich micro-foundations). With competitive search, the share of the 
surplus in bilateral trade changes with the market tightness, since this share is given by the elasticity of buyer's matching probability. With the particular matching function that we use, moreover, this share is highly responsive to changes in the market tightness and hence so is the price. The next step in our research agenda is to investigate the quantitative contribution of each of these factors to the behavior of prices.

We have assumed throughout this paper that non traders cannot buy houses. We have done so for simplicity, but we are aware that depending on the market tightness and on the probability of becoming mismatched, non-traders may prefer to buy an additional house as an insurance mechanism against becoming mismatched. Notice that in our benchmark calibration the average tenure length is 10 years. That is, on average, a non-trader becomes mismatched in 10 years, whereas the model period is a week. Hence, our intuition tells us that our assumption cannot be too stringent. Nevertheless, we plan to allow non traders to buy a second house to quantify how important this insurance effect is.

Finally, we want to analyze the transitional dynamics of the model as well as its stochastic version to study price volatility. 


\section{Appendix}

\section{Proof of Proposition 1}

It is equivalent to consider the sign effects of changes in the vacancy rate $V$ and in the housing stock $H$, since $H=\frac{1}{1-V}$. From (39), $\theta$ is decreasing in $H$ with

$$
\frac{d \theta}{d H}=\frac{-\alpha}{(H-1)^{2}\left[\alpha+(1-\eta(\theta)) m^{b}(\theta) q\right]} .
$$

Then (23) and (24) imply that $\pi^{s}$ falls and $\pi^{b}$ rises when $H$ rises (since $m^{s}(\theta)$ is increasing and $m^{b}(\theta)$ is decreasing in $\theta$ ). Also, (29) implies that $s$ increases with $H$.

From (37), $\frac{d b}{d H}=\frac{d \theta}{d H}(H-1)+\theta$. Using (48) and rearranging, we may write

$$
\frac{d b}{d H}=\frac{-1+\theta(H-1)\left[1+(1-\eta(\theta)) m^{b}(\theta) \frac{q}{\alpha}\right]}{(H-1)\left[1+(1-\eta(\theta)) m^{b}(\theta) \frac{q}{\alpha}\right]} .
$$

The denominator in (49) is positive, whereas the numerator in (49) can be written as

$$
-(H-1)\left(1+\eta(\theta)\left(\frac{2-H}{H-1}-\theta\right)\right)=-(H-1)\left(1+\eta(\theta) m^{b}(\theta) \theta \frac{q}{\alpha}\right)<0
$$

using (48). So $b$ decreases with $H$.

From (31), the sign effect of changes in $H$ on $n$ and sales $\pi^{s} s$ is the same. Sales are given

by $m^{b}(\theta) \theta q(H-1)$. It is direct to show that the derivative of this term with respect to $H$ is proportional and has the same sign as the term

$$
(1-\eta(\theta)) \frac{d \theta}{d H}(H-1)+\theta
$$

which in turn may be written as

$$
\frac{\alpha s[-1+\eta(\theta)(1+\theta)]}{(H-1)\left[\alpha+(1-\eta(\theta)) m^{b}(\theta) q\right]}
$$

using (28), (30), (39) and (48). Since the denominator in (52) is positive, sales and $n$ increase with $H$ if $\eta(\theta)(1+\theta)>1$, and they decrease if $\eta(\theta)(1+\theta)<1$. Equivalently, since $\eta(\theta)(1+\theta)$ is an increasing function of $\theta$, sales increase with $H$ if $\theta>\theta_{s}$, and they decrease if $\theta<\theta_{s}$ 
where $\theta_{s}$ satisfies $\eta\left(\theta_{s}\right)\left(1+\theta_{s}\right)=1$.

Finally, (42) and (43) imply that $S$ falls when $H$ rises since both $m^{b}(\theta)$ and $1-\eta(\theta)$ are decreasing functions.

\section{Proof of Proposition 2}

From (39), $\theta$ increases with $\alpha$. From (23) and (24), $\pi^{b}$ then decreases and $\pi^{s}$ increases with $\alpha$. Also, since $s$ is independent of $q$ (equation (29)), (30) implies that $b$ increases with $\alpha$. Hence, from (28), $n$ decreases with $q$. Sales $\pi^{s} s$ also increase.

\section{Proof of Proposition 3}

From (39), $\theta$ decreases with $q$. From (23), $\pi^{b}$ then increases with $q$. Also, since $s$ is independent of $q$, (30) implies that $b$ decreases with $q$. From (28) $n$ then increases with $q$. From (31), sales $\pi^{s} s$ then also increase, and (since $s$ is constant) so does $\pi^{s}$.

From (42) and (43) the bilateral surplus $S$ decreases with $q$.

\section{Proof of Propositions 4 and 5}

Since $\theta>1, \pi^{b}=\theta^{-1}, \pi^{s}=1, S^{b}=S$ and $S^{s}=0$, so the steady state is characterized by:

$$
\begin{aligned}
s & =H-1, \\
b & =\theta s \\
n & =2-H-\theta(H-1), \\
\alpha n & =s \\
(1-\beta) W^{b} & =\underline{v} \\
(1-\beta) W^{s} & =\bar{v}+S \\
(1-\beta) W^{n} & =\bar{v}-\beta \alpha\left(W^{n}-W^{b}\right), \\
S & =\bar{v}-\underline{v}+\beta(1-\alpha)\left(W^{n}-W^{b}\right), \\
p & =\bar{v}-\underline{v}+\beta\left(W^{s}-W^{b}\right) .
\end{aligned}
$$


Combining (57), (59) and (60),

$$
W^{n}-W^{b}=S=\frac{\bar{v}-\underline{v}}{1-\beta(1-\alpha)} .
$$

Consider an increase of the housing stock $H$. From (53) and (56), both $s$ and $n$ increase, so $b$ and hence $\theta$ must fall. Then $\pi^{b}$ increases while $\pi^{s}$ remains constant. Sales $\pi^{s} s$ increase. From (62) and (57)-(59) and (61), $W^{b}, W^{s}, W^{n}, S$ and $p$ are all independent of $H$.

Suppose now that $\alpha$ increases. From (56), $n$ must fall (since $s$ is constant), and so $b$ must increase. Then $\theta$ increases, so $\pi^{b}$ falls, while $\pi^{s}$ remains constant. Sales $\pi^{s} s$ also remain constant. From (62), $W^{n}-W^{b}$ and $S$ fall. Then $W^{s}$ falls from (58) and, since $W^{b}$ remains constant (equation (57)), $W^{n}$ falls as well. Finally, (61) implies that $p$ falls.

\section{Proof of Proposition 6}

When $\theta<1, \pi^{b}=1, \pi^{s}=\theta, S^{b}=S$ and $S^{s}=0$, so the steady state is characterized by:

$$
\begin{aligned}
s & =H-1, \\
b & =\theta(H-1), \\
n & =2-H-\theta(H-1), \\
\alpha n & =\theta s, \\
(1-\beta) W^{b} & =\underline{v}+S, \\
(1-\beta) W^{s} & =\bar{v} \\
(1-\beta) W^{n} & =\bar{v}-\beta \alpha\left(W^{n}-W^{b}\right), \\
S & =\bar{v}-\underline{v}+\beta(1-\alpha)\left(W^{n}-W^{b}\right) . \\
p & =\beta\left(W^{s}-W^{n}\right)
\end{aligned}
$$

Combining (63), (65), and (66),

$$
\frac{\alpha}{1+\alpha}\left(\frac{2-H}{H-1}\right)=\theta \text { or } \frac{\alpha}{1+\alpha}\left(\frac{1}{V}-2\right)=\theta
$$

Combining (67)-(70), $W^{n}=W^{b}=W^{s}=\frac{\bar{v}}{1-\beta}$. So $S=\bar{v}-\underline{v}$, and $p=0$. 
Consider an increase of the housing stock $H$ or the vacancy rate $V$. From (72), $\theta$ falls, so $\pi^{s}$ falls while $\pi^{b}$ remains constant. From (72), sales as a fraction of the stock $\pi^{s} V$ are given by $\frac{\alpha}{1+\alpha}(1-2 V)$, so they also fall. As noted above, $W_{b}, W_{s}, W_{n}, S$ and $p$ are all independent of $V$.

Suppose now that $\alpha$ increases. From (72), $\theta$ increases, so $\pi^{s}$ increases, while $\pi^{b}$ remains constant. Sales $\pi^{s} s$ then also increase (since $s$ is constant). Again, $W_{b}, W_{s}, W_{n}, S$ and $p$ are independent of $\alpha$.

Table 1: Calibration

\begin{tabular}{l|l|l}
\hline \hline Param. & Observation & Value \\
\hline$N$ & - & 100 \\
$H$ & vac. rate $1985-2001=1-\mathrm{N} / \mathrm{H}=1.5 \%$ & 101.52 \\
$q$ & time to buy $=\frac{1}{q m^{b}(\theta)}=8$ weeks & 0.1972 \\
$\alpha$ & tenure $=\frac{1-\alpha}{\alpha}+\frac{1}{q m^{b}(\theta)}=10$ years & 0.0019 \\
$\beta$ & - & $0.96^{1 / 52}$ \\
$\bar{v}$ & - & $1=1274.32(1-\beta)$ \\
$\underline{v}$ & - & $0.1=127.43(1-\beta)$ \\
\hline
\end{tabular}

Table 2: Steady State

\begin{tabular}{l|l}
\hline \hline$\theta$ & 0.99 \\
Sellers $s / N(\%)$ & 1.52 \\
Buyers $b / N(\%)$ & 1.51 \\
Non-traders $n / N(\%)$ & 96.96 \\
Sales $\pi^{s}(\theta)(H-N) / H(\%)$ & 0.19 \\
Average time to sell $1 / \pi^{s}(\theta)$ & 8.06 \\
Price $p$ & 814.56 \\
Seller surplus $S_{s} / S(\%)$ & 41.56 \\
Bilateral surplus $S$ & 11.91 \\
\hline
\end{tabular}

Table 3: Increase in vacancy rate from 1.5 to $4 \%$

\begin{tabular}{l|r|r|r}
\hline \hline & Vac. Rate 1.5\% & Vac. Rate $4.0 \%$ & Change \\
\hline Price & 814.57 & 52.82 & -93.52 \\
Sales (\% of stock) & 0.19 & 0.18 & -4.74 \\
Aver. time to sell & 8.06 & 22.55 & 179.94 \\
Aver. time to buy & 8.00 & 5.75 & -28.18 \\
Seller's share & 0.42 & 0.12 & -70.66 \\
\hline
\end{tabular}


Table 4: Decrease in tenure from 10 to 7 years

\begin{tabular}{l|r|r|r}
\hline \hline & $\begin{array}{r}\text { Tenure 10 years } \\
(\alpha=0.0019)\end{array}$ & $\begin{array}{r}\text { Tenure 7 years } \\
(\alpha=0.0028)\end{array}$ & Change (\%) \\
\hline Price & 814.57 & 5784.48 & 610.13 \\
Sales (\% of stock) & 0.19 & 0.26 & 40.95 \\
Aver. time to sell & 8.06 & 5.72 & -29.06 \\
Aver. time to buy & 8.00 & 12.48 & 56.00 \\
Seller's share & 0.42 & 0.72 & 73.90 \\
\hline
\end{tabular}



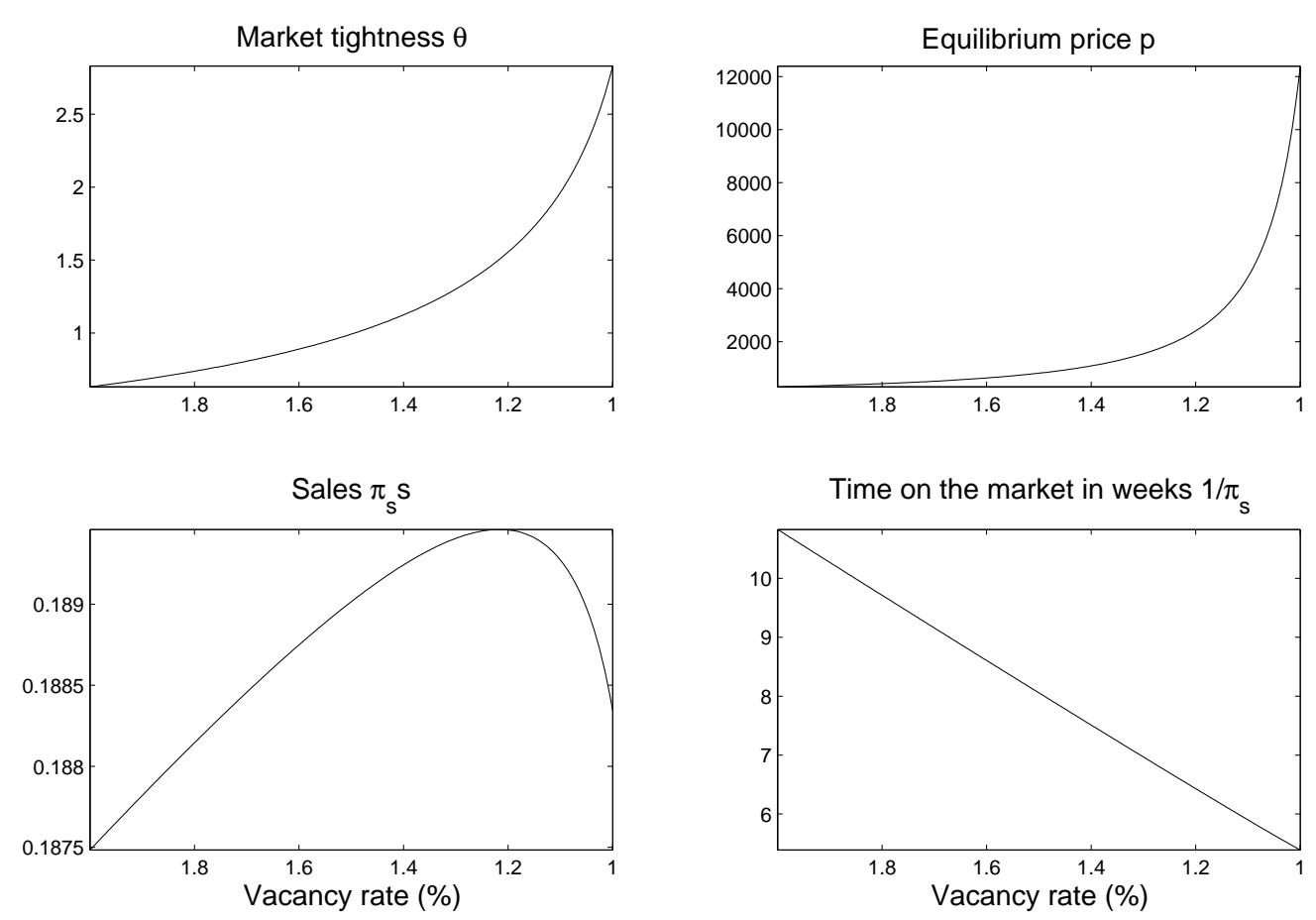

Figure 1: Comparative statics for different values of the housing stock (I). $\beta=0.96$ in annual terms, $q=0.1972, \alpha=0.0019$, and $\bar{v}=1$. 

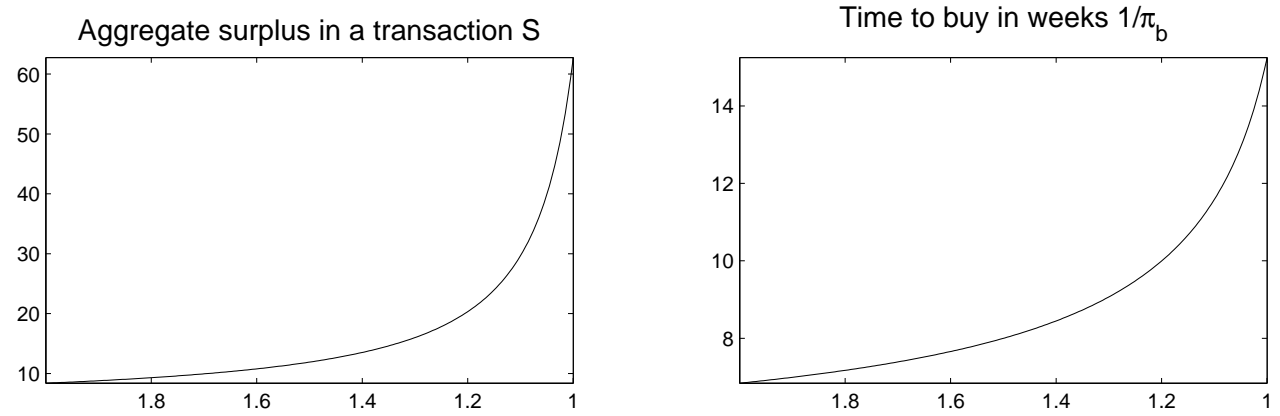

Seller surplus as a fraction of aggregate surplus $S_{s} / S$

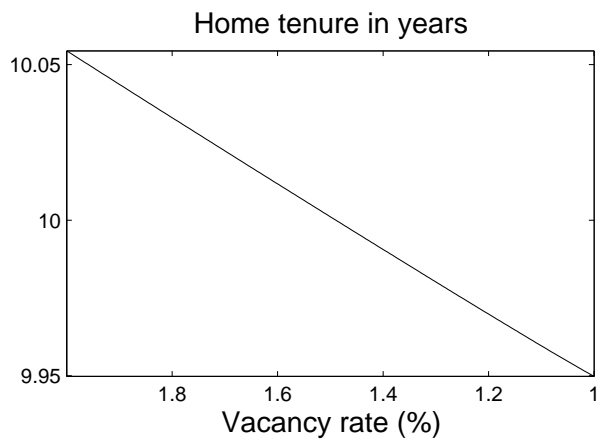

Figure 2: Comparative statics for different values of the housing stock (II). $\beta=0.96$ in annual terms, $q=0.1972, \alpha=0.0019$, and $\bar{v}=1$. 

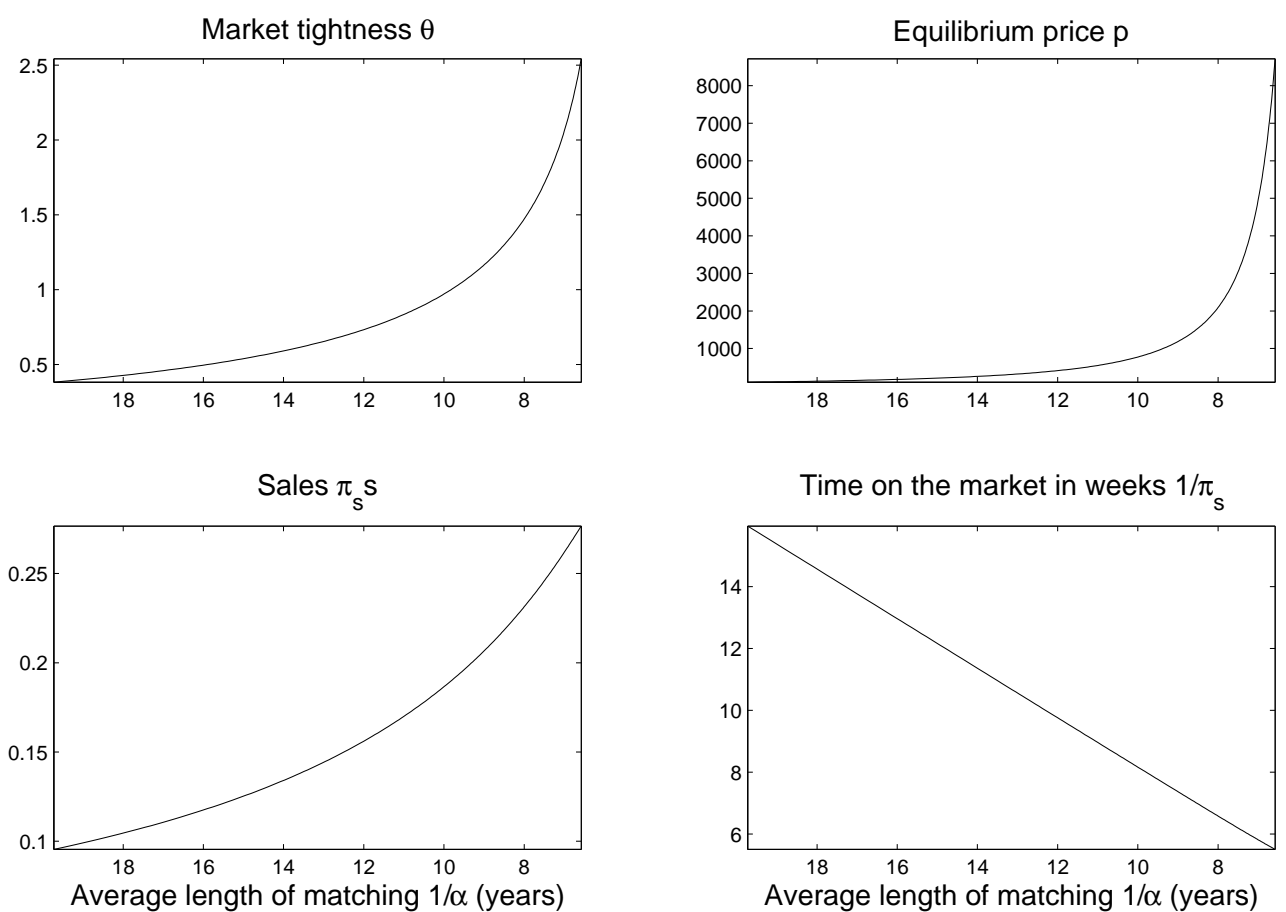

Figure 3: Comparative statics for different values of the mobility parameter $\alpha$ (I). $\beta=0.96$ in annual terms, $q=0.1972$, the vacancy rate is 1.5 percent, and $\bar{v}=1$. 

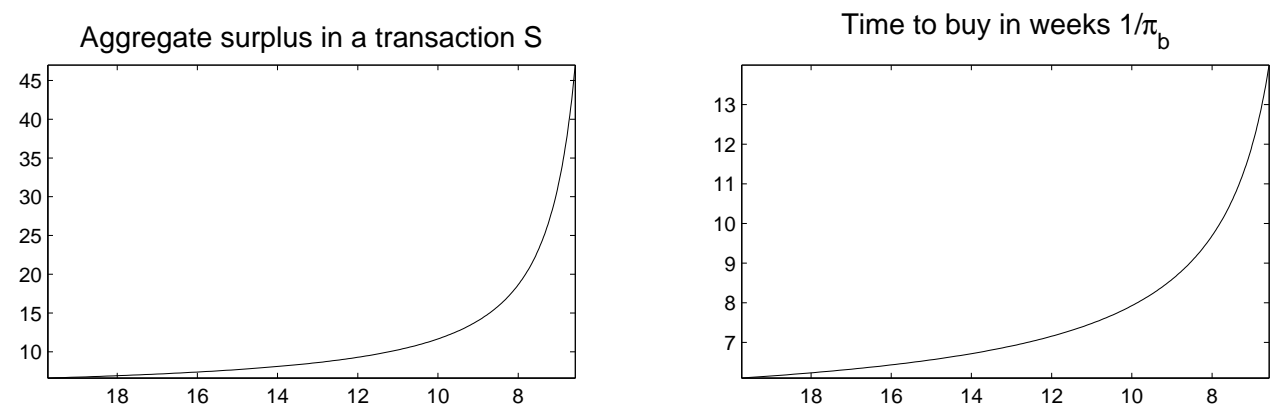

Seller surplus as a fraction of aggregate surplus $S_{S} / S$
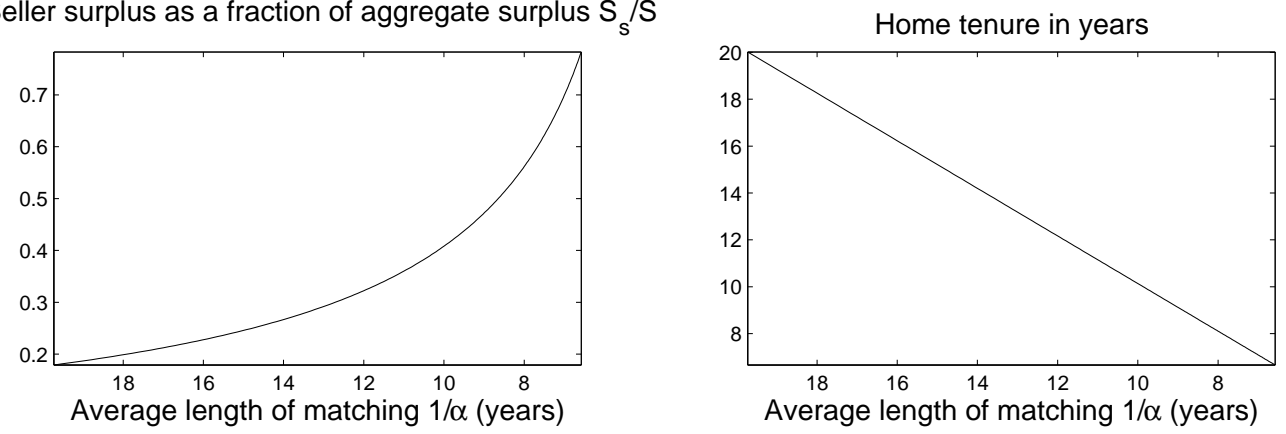

Figure 4: Comparative statics for different values of the mobility parameter $\alpha$ (II). $\beta=0.96$ in annual terms, $q=0.1972$, the vacancy rate is 1.5 percent, and $\bar{v}=1$. 

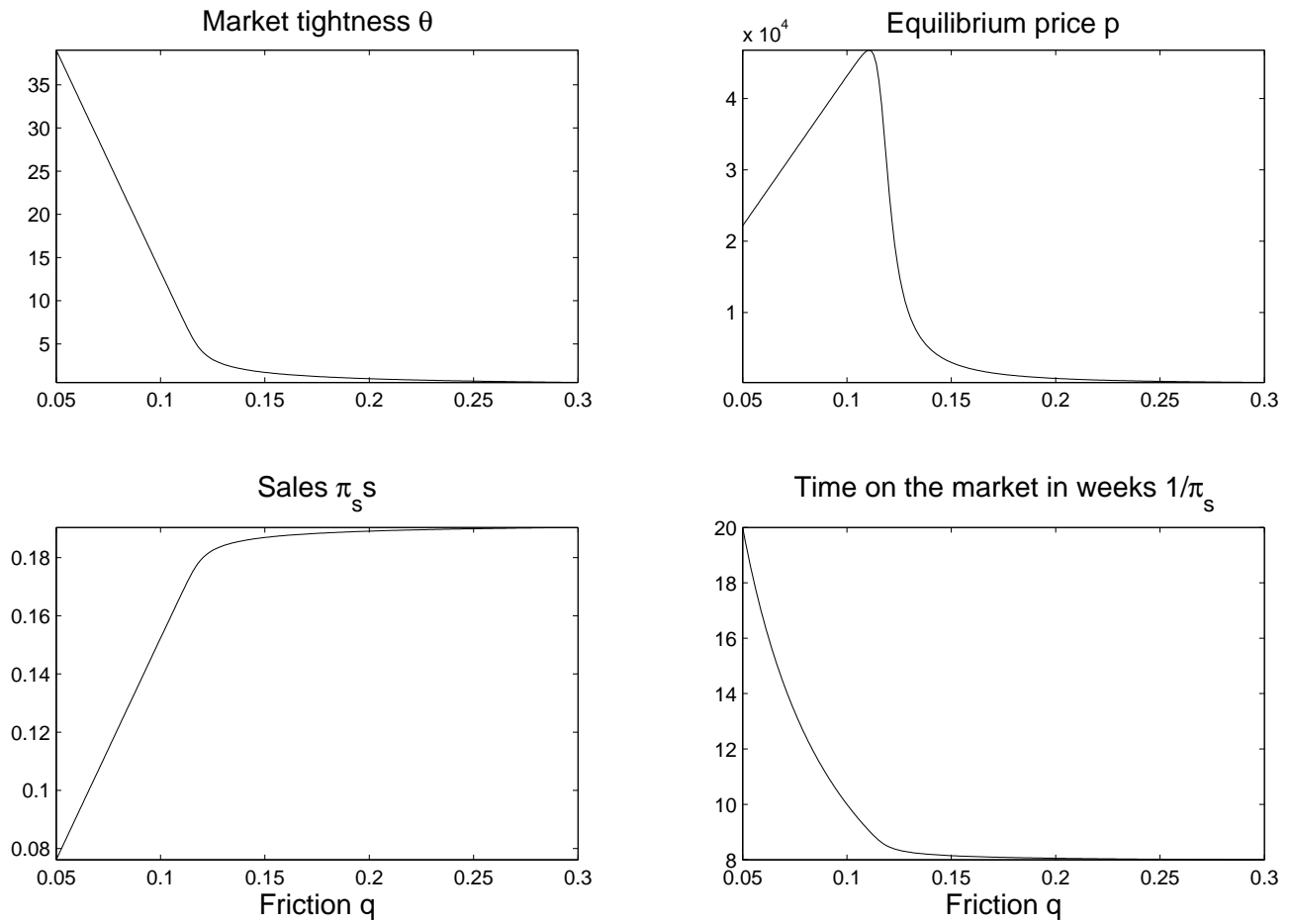

Figure 5: Comparative statics for different values of the friction parameter $q$ (I). $\beta=0.96$ in annual terms, $\alpha=0.0019$, the vacancy rate is 1.5 percent, and $\bar{v}=1$. 

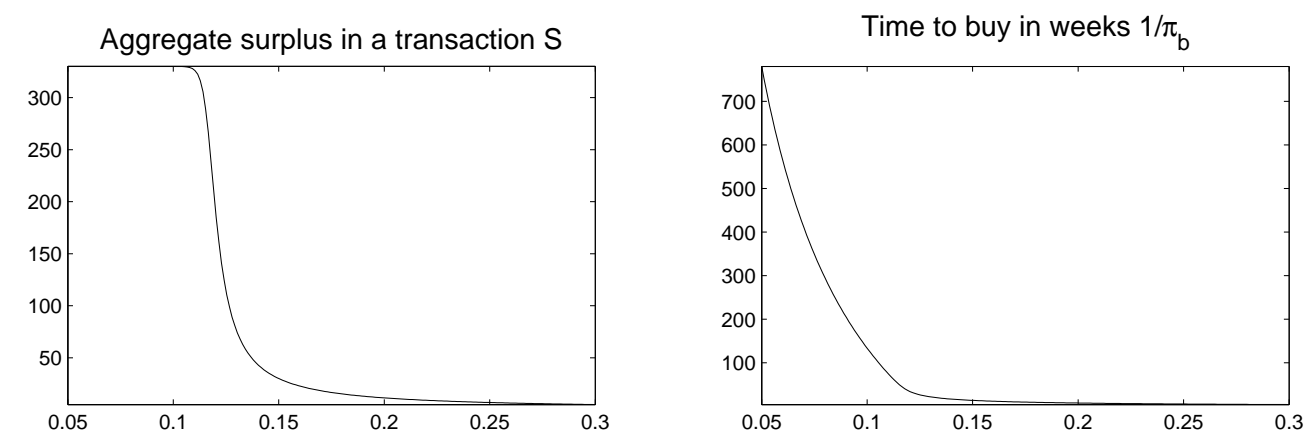

Seller surplus as a fraction of aggregate surplus $S_{S} / S$

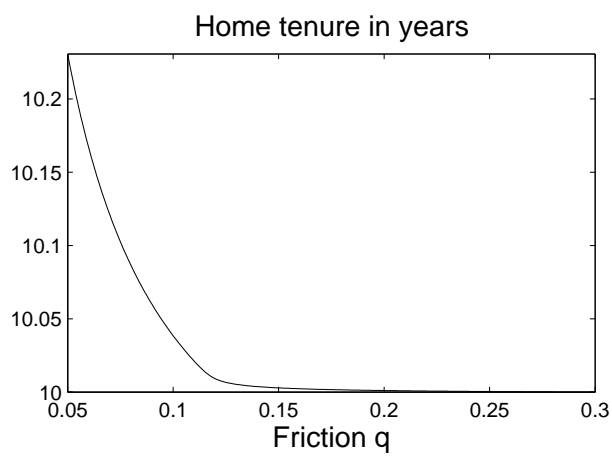

Figure 6: Comparative statics for different values of the friction parameter $q$ (II). $\beta=0.96$ in annual terms, $\alpha=0.0019$, the vacancy rate is 1.5 percent, and $\bar{v}=1$. 

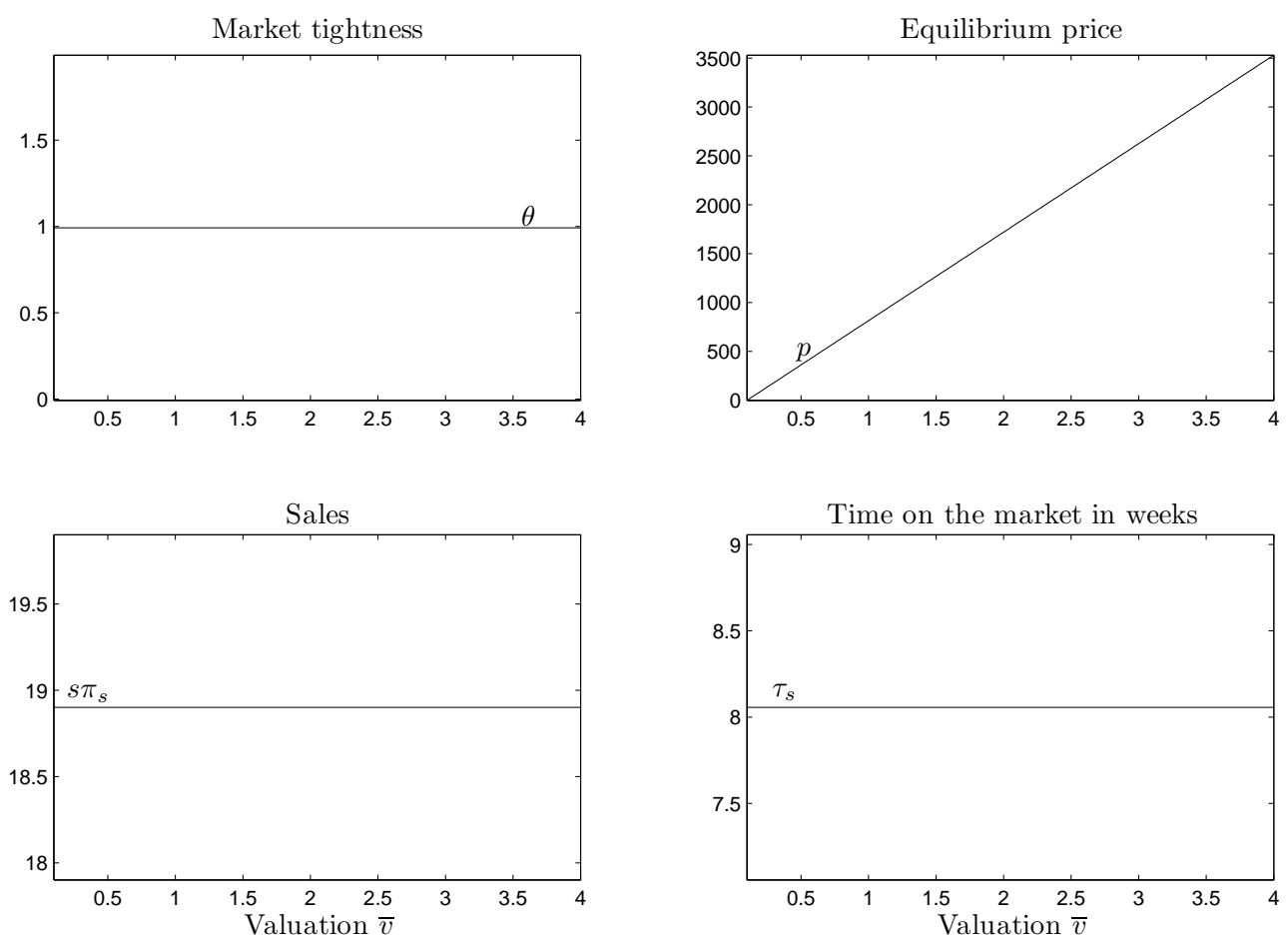

Figure 7: Comparative statics for different values of the valuation parameter $\bar{v} \cdot \beta=0.96$ in annual terms, $\alpha=0.0019, q=0.1972$, and the vacancy rate is 1.5 percent.
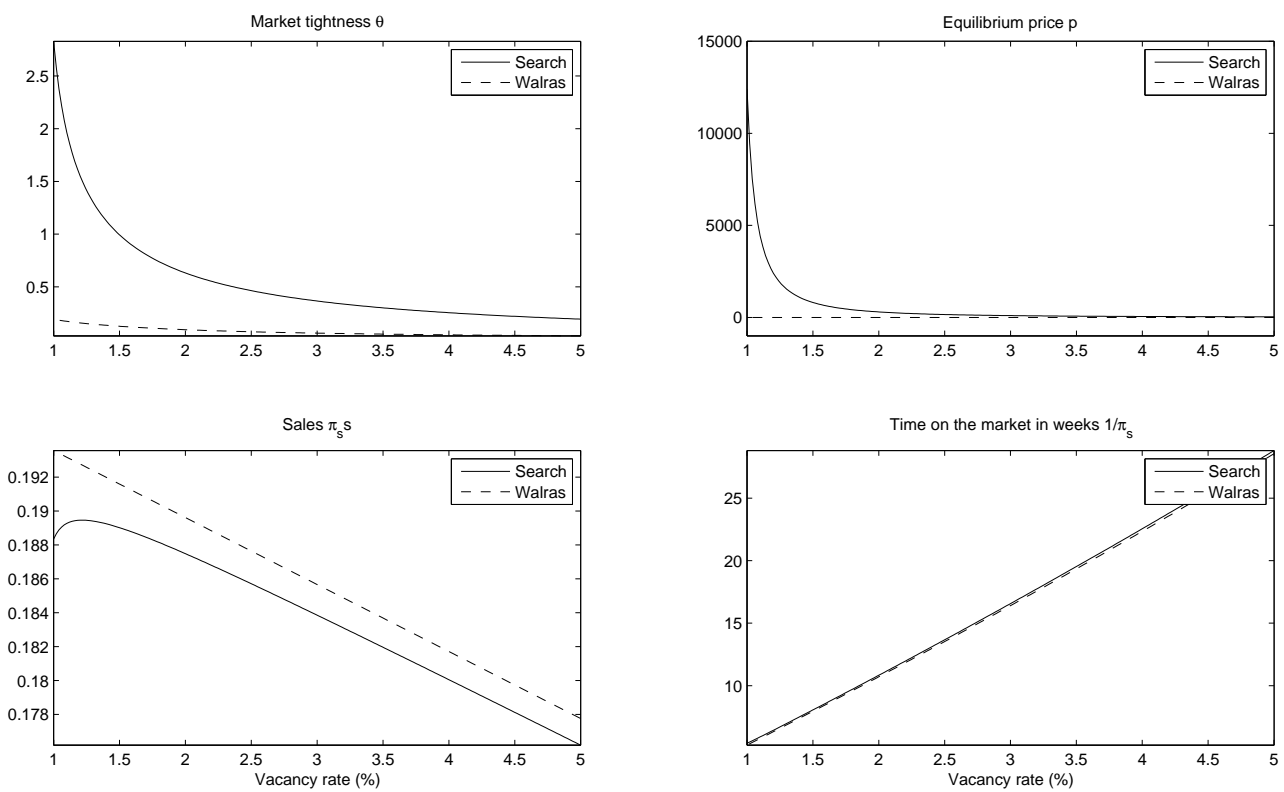

Figure 8: Search and Walrasian steady states for different vacancy rates. $\beta=0.96$ in annual terms, $\alpha=0.0019, q=0.1972$. 

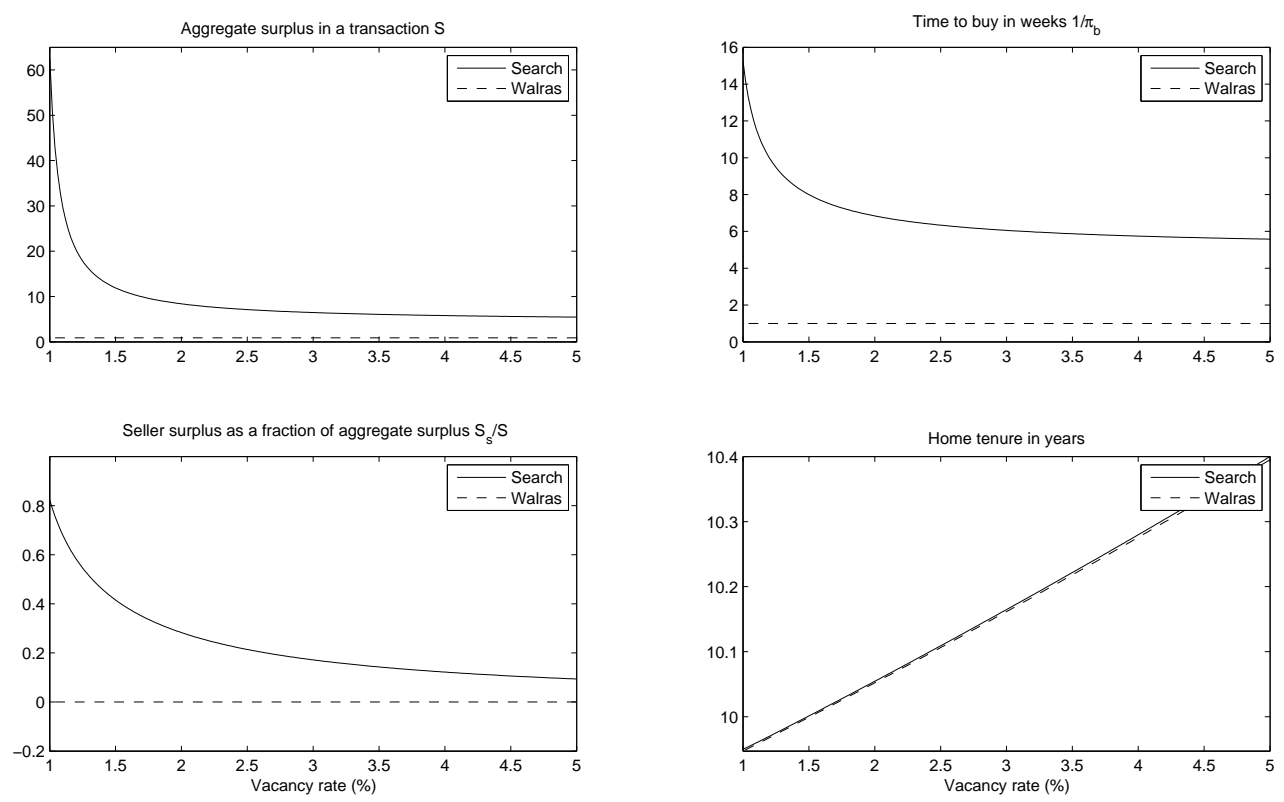

Figure 9: Search and Walrasian steady states for different vacancy rates. $\beta=0.96$ in annual terms, $\alpha=0.0019, q=0.1972$.
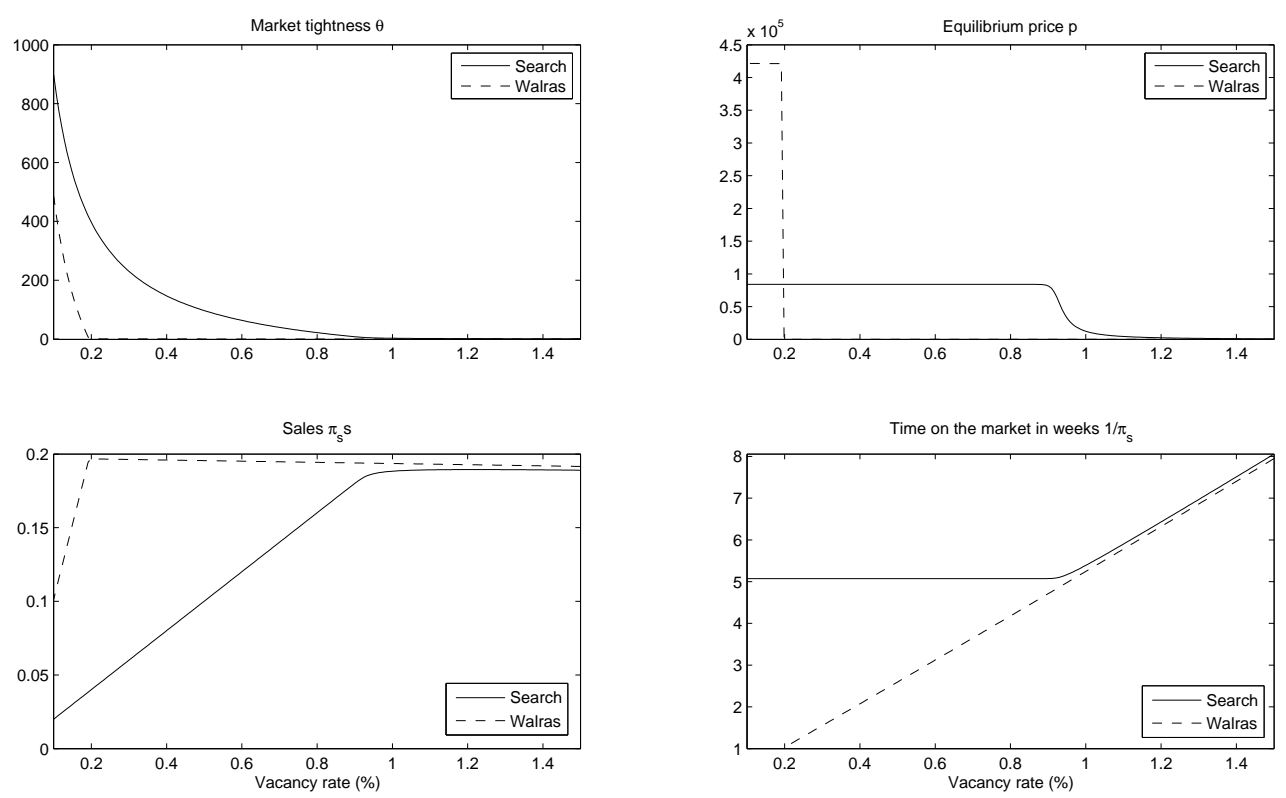

Figure 10: Search and Walrasian steady states for different vacancy rates. $\beta=0.96$ in annual terms, $\alpha=0.0019, q=0.1972$. 

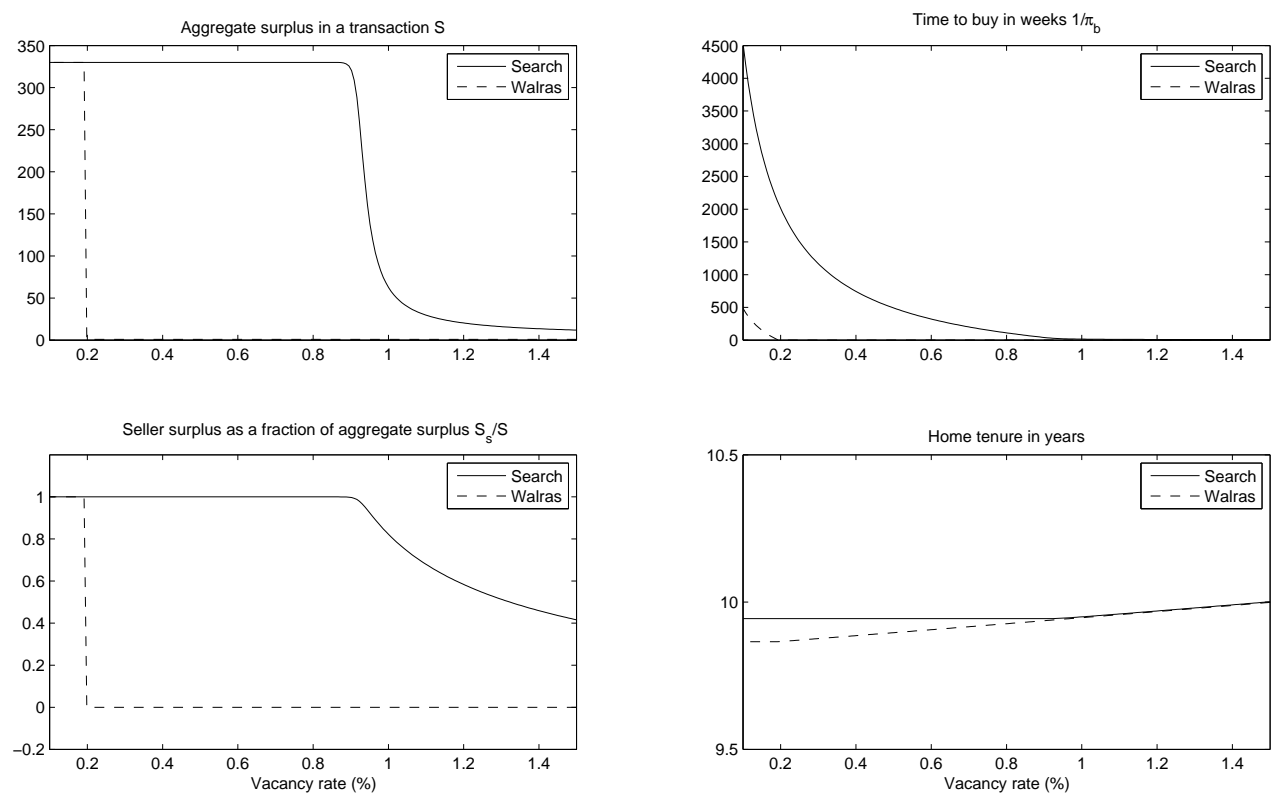

Figure 11: Search and Walrasian steady states for different vacancy rates. $\beta=0.96$ in annual terms, $\alpha=0.0019, q=0.1972$. 


\section{References}

Albrecht, J., A. Anderson, E. Smith, and S. Vroman (2007). Opportunistic matching in the housing market. International Economic Review 48(2), 641-664.

Arnold, M. A. (1999). Search, bargaining and optimal asking prices. Real Estate Economics $27(3), 453-481$.

Burdett, K., S. Shi, and R. Wright (2001). Pricing and matching with frictions. Journal of Political Economy 109(5), 1060-1085.

Davis, M. A. and J. Heathcote (2005). Housing and the business cycle. International Economic Review 46(3), 751-84.

Díaz, A. and M. J. Luengo-Prado (2006). The wealth distribution with durable goods. Economics Working Papers we067027, Universidad Carlos III, Departamento de Economía.

Díaz, A. and M. J. Luengo-Prado (2008). On the user cost and homeownership. Review of Economic Dynamics 11(3), 584-613.

Genesove, D. and C. J. Mayer (1997). Equity and time to sale in the real estate market. American Economic Review 87(3), 255-69.

Glaeser, E. L. and J. Gyourko (2006). Housing dynamics. NBER Working Papers 12787, National Bureau of Economic Research, Inc.

Hendel, I., A. Nevo, and F. Ortalo-Magné (2007). The relative performance of real estate marketing platforms: Mls versus fsbomadison.com. NBER working papers, National Bureau of Economic Research, Inc.

Hosios, A. J. (1990). On the efficiency of matching and related models of search and unemployment. Review of Economic Studies 57(2), 279-98.

Krainer, J. (2001). A theory of liquidity in residential real estate markets. Journal of Urban Economics 49(1), 32-53.

Krainer, J. (2008). Falling house prices and rising time on the market. FRBSF Economic Letter (Mar 21).

Merlo, A. and F. Ortalo-Magné (2004). Bargaining over residential real estate: evidence from england. Journal of Urban Economics 56(2), 192-216. 
Merlo, A., F. Ortalo-Magné, and J. Rust (2007). Bargaining and price determination in the residential real estate market. Mimeo.

Moen, E. R. (1997, April). Competitive search equilibrium. Journal of Political Economy $105(2), 385-411$.

Montgomery, J. D. (1991). Equilibrium wage dispersion and interindustry wage differentials. The Quarterly Journal of Economics 106(1), 163-179.

Nakajima, M. (2005). Rising earnings instability and prices of housing and financial assets. Mimeo.

Peters, M. (1991, September). Ex ante price offers in matching games non-steady states. Econometrica 59(5), 1425-54.

Ríos-Rull, J. and V. Sanchez-Marcos (2007). House price movements. Mimeo.

Shimer, R. (1996). Contracts in a frictional labor market. Mimeo.

Stein, J. C. (1995). Prices and trading volume in the housing market: A model with down-payment effects. The Quarterly Journal of Economics 110(2), 379-406.

VanNieuwerburgh, S. and P.-O. Weill (2006). Why has house price dispersion gone up? Nber working papers, National Bureau of Economic Research, Inc.

Wheaton, W. C. (1990). Vacancy, search, and prices in a housing market matching model. Journal of Political Economy 98(6), 1270-92.

Williams, J. T. (1995). Pricing real assets with costly search. Review of Financial Studies $8(1), 55-90$.

Yavaş, A. (1992). A simple search and bargaining model of real estate markets. Real Estate Economics 20(4), 533-548.

Yui, C. K. and J. Zhang (2007). Housing markets with competitive search. 